\title{
The Effects of Official Bond Market Intervention in Europe
}

\author{
Michiel De Pooter, Robert F. Martin and Seth Pruitt* \\ Federal Reserve Board of Governors
}

September 2012

First version: November 2011

\begin{abstract}
The ECB's purchases of sovereign debt provide a unique opportunity for testing the effects of large-scale asset purchase programs. To understand the channels through which the ECB influences prices, we develop a search-based asset pricing model with default. Empirical estimates of official intervention's effects suggest that ECB purchases led to significant temporary and lasting decreases in sovereign bond liquidity premia.
\end{abstract}

Keywords: bond, credit default swap, European debt crisis, liquidity risk, default risk, term structure, search and matching, asset pricing

EFM codes: 550, 560, 570

\footnotetext{
${ }^{*}$ De Pooter: michiel.d.depooter@frb.gov; Martin: robert.f.martin@frb.gov; Pruitt: seth.j.pruitt@frb.gov. The views and opinions are those of the authors and do not reflect the views and opinions of the Federal Reserve Board, the Federal Reserve System, or their respective staffs.
} 
In response to the global financial crisis, most major-economy central banks reduced policy rates to the effective lower bound. Although loosening policy on such a large and broad scale was unprecedented, the monetary accommodation was seemingly insufficient to counteract the effect of the crisis and its aftermath. As a result, central banks have undertaken a number of non-standard monetary policy programs to further ease policy. Most of these programs have involved some form of large-scale asset purchases. For example, the Federal Reserve conducted two large-scale asset purchase programs, nearly tripling its balance sheet and the Bank of England plans to purchase nearly 350 billion pounds of sovereign debt.

Yet, despite the wide-spread use of these programs and general acceptance of them among the central banking community, evidence of their success is somewhat mixed. Even among those who fervently believe that the programs have been effective, there has been considerable debate over the channels through which the programs work. ${ }^{1}$ Main-stream frictionless, financial market models (including the large-scale DSGE models favored by central banks) feature perfect asset substitution. This feature of standard models essentially precludes central bank actions from influencing the relative price of different classes of assets.

Aware of this debate, in early May 2010, the European Central Bank (ECB) began to purchase substantial quantities of sovereign debt from member nations via its Securities Markets Programme (SMP). This intervention had the explicit goal of ensuring depth and liquidity in 'dysfunctional' markets. The ECB believed that liquidity conditions in certain sovereign bond markets had deteriorated sufficiently that the markets were no longer functioning well, and intervened with the specific intention of improving liquidity conditions but without trying to change the fundamental value of the asset - in a way, sidestepping the key issue over whether or not these interventions might, despite their intentions, change the relative price of sovereign bonds.

These operations provide a unique opportunity for testing the efficacy of these types of large-scale asset purchase programs. We use a term structure model to decompose bond prices into parts describing the risk free rate, default intensity, and a liquidity premium. Using bonds alone, we cannot distinguish the last two terms. However, because the interventions are conducted on sovereign bonds in countries with well-functioning, liquid CDS markets, we have a measure of the probability of default that is not directly linked to liquidity conditions in bond markets. In addition, because the ECB sterilized these operations, the effect of SMP purchases on the risk free rate (as measured by relevant maturity German bond yields) should be negligible. That is, we should not expect these operations to influence either the expected path of short rates or the rate of overall European growth. In any case, we are able to control for fluctuations in the risk free rate directly.

Having the default probability and the risk free rate, in practice, allows us to control for a significant amount of variation in bond prices unrelated to the ECB intervention and allow us to achieve more precise estimates of the effect of purchases on bond liquidity. In addition, the ECB made SMP purchases off and on over a long period of time and made these

\footnotetext{
${ }^{1}$ Noteworthy are the findings of D'Amico and King (forthcoming) and D'Amico, English, Lopez-Salido and Nelson (2012) that use a preferred-habitat motivation to find stock and flow effects of Federal Reserve large-scale asset purchases. They find significant effects from the purchases, the latter paper identifying the effects primarily through the real term premium. Our findings complement theirs and suggests an economic friction that causes the effects to come via the real term premium channel.
} 
purchases in five distinct sovereign markets beginning with Greece, Ireland, and Portugal in May 2010 and then expanding the program to Spain, and Italy on August 7, 2011. The structure of these purchases allows us to exploit both cross-section and time series elements of the data.

To understand the channels through which the ECB can influence market functioning, we develop a search-based asset pricing model with default. Our own informal analysis of the evidence combined with the ECB's belief that it has responded to market dysfunction motivates our theoretical model for bonds. Our theory modifies the framework of Darrel Duffie, Nicolae Garleanu and Lasse Heje Pedersen (2005, 2007) (DGP hereafter) and sheds light into how these risks manifest in bond and CDS yield spreads over time. Since a key feature of the European sovereign market over the relevant period is a steady increase in the probability of default, we modify the model to explicitly include default.

The model naturally produces a liquidity premium on top of the default premium and the asset's fundamental value by providing an explicit explanation for liquidity risk: The risk that an agent cannot immediately sell an asset for the equilibrium price due to search frictions. This risk of delay then translates into an equilibrium liquidity premium on bond purchases.

We interpret official intervention an exogenous reduction in the supply of bonds traded amongst investors caused by officials instantaneously purchasing bonds from agents wanting to sell. We show that this exogenous shock affects the model's steady-state and typically exhibits transition dynamics in the process of moving to its new long-run values. Therefore we provide a theoretical justification for the existence of a permanent stock effect and a temporary flow effect of official purchases, a key feature missing in standard models.

Using the model as a lens on the data, we provide empirical estimates of the effect of the purchases within a framework that nests alternative theoretical perspectives. We estimate changes in bond liquidity via feasible generalized least squares. Consistent with the model, we allow the ECB's purchases to increase bond-market liquidity through both a stock and a flow channel. We find both are economically and statistically significant.

Of note, the model implies a novel relationship between the probability of default and the liquidity premium. ${ }^{2}$ Our model links liquidity premia to the risk that the asset owner is unable to immediately find a buyer when they are desperate to sell. Because the expected time spent waiting to sell is reduced by a decrease in the expected time until the asset defaults (paying out a final cash payment), an increase in the probability of default reduces the liquidity premium in our model. We control for the default intensity in our empirics and find support for this mechanism. This stands apart from recent theoretical work on corporate bonds in He and Milbradt (2012) in which increasing default risk leads to increasing liquidity premia, which we view as reflecting the difference in default recovery wait times between corporate and sovereign defaults.

\footnotetext{
${ }^{2}$ Typically, one thinks of an increase in the probability of default as being associated with an increase in the liquidity premium. This correlation arises naturally in the data as increased default probabilities are often correlated with other forms of market distress and dysfunction. However, in our theory a different mechanism is at play. If these unmodeled forces were significant, we'd expect them to swamp the effect our theory predicts going in the opposite direction - we do not find this to be the case in our data.
} 
The paper is organized as follows. Section 1 presents the data and describes its evolution in the context of European events. Section 2 presents the search-based asset pricing model, reports theoretical and numerical results to better understand its mechanisms. Section 3 provides our model-based interpretation of the estimated effects of the European Central Bank's bond market intervention. We then conclude. The appendix contains proofs and detailed discussion of our term-structure approach to measuring bond market liquidity

\section{Data}

We collect data for six European countries. In five countries, the ECB is known to have purchased sovereign debt under its Securities Markets Programme - Portugal, Ireland, Greece, Italy and Spain. We include France as a control country. Although the ECB has yet to purchase French debt under the SMP, France has experienced several episodes of market pressure, which we interpret of periods of near market dysfunction.

For each country we collected daily CDS spreads and bond price data for the sample January 1, 2009 through February 29, 2012. Our sovereign bond price data is from Datastream. We collected prices for all bonds that were outstanding for each day in our sample. We apply the usual filters to the data; we delete any bonds that have option-like features or floating coupon payments, we do not include any Treasury Bills, and we exclude any bond in the estimation as soon as it has less than three months left to maturity. ${ }^{3}$ With the full set of characteristics in hand for each bond (maturity date, coupon rate, coupon payment frequency) we use the methodology described belwo to estimate zero-coupon curves for each day from which we then compute the term structure of default probabilities. We use German zero-coupon yields for maturities between 3 months and 10 years are our risk free interest rates. We construct these using the Svensson-Nelson-Siegel parameters that we obtained from the Bundesbank. ${ }^{4}$

Our source for sovereign CDS spreads is Mark-it Partners and we collect mid-quotes on eight CDS contract maturities: 6 months and 1, 2, 3, 4, 5, 7 and 10 years. All contracts are denominated in U.S. dollars, even though these are designed to offer default risk protection on euro-denominated sovereign bonds. The reason behind this currency mismatch is that the overwhelming majority of trading occurs in U.S. dollar-denominated contracts. ${ }^{5}$ Finally, we download 6-month euro-area LIBOR and euro-swap rates from Bloomberg.

The main source of data on the ECB's bond market purchases come directly from the SMP entry on the ECB's balance sheet which is publicly available at the weekly frequency. ${ }^{6}$ In addition, the ECB has provided some information as to which bonds are purchased when. For instance, early purchases under the program, beginning in 2010, were only of Greek, Portuguese and Irish bonds. The expansion of the SMP to Spain and Italy began in August

\footnotetext{
${ }^{3}$ See Gürkaynak, Sack and Wright (2007) for further details.

${ }^{4}$ These are available on http://www.bundesbank.de/statistik/statistik_zeitreihen.en.php.

${ }^{5}$ Chen, Fleming, Jackson, Li and Sarkar (2011) analyze all the trades entered into the DTCC warehouse between May and July 2010 and find that only a small fraction of the sovereign single-name trades were in euros.

${ }^{6}$ This is available on http://www.ecb.int/press/pr/wfs/.
} 
2011. Barclays Capital, who has been a significant counterparty to ECB transactions during our data sample, has published weekly country breakdowns of SMP purchases and we use their estimates to allocate total SMP purchases across countries at each point in time. ${ }^{7}$ The estimates primarily reflect a rule of proportionality (buying that is proportionate to nations' bond market size), but additionally adjusts according to differential market pressures (week-by-week) as was observed by the bank's trading desk and according to occasional announcements by the ECB of its purchase composition.

For details on how we make use of these data in a term-structure framework to measure the relative liquidity premium of sovereign bonds versus credit default swaps, see the appendix. In essence, we calculate a modified CDS basis using the entire term structure, thus ensuring that we capture the effects of ECB purchases even they fall on maturities other than the five-year maturity upon which we focus.

\subsection{The Evolution of European Crisis and the ECB's Actions}

In May 2010, the sovereign markets of several euro-area countries, came under extreme pressure as mounting financial market concerns about the general fiscal health of these countries, especially that of Greece, came to a head. According to contemporaneous statements from the ECB, the functioning of several segments of the financial markets became seriously impaired at this time, including money markets, foreign exchange markets, and most importantly for the present study, sovereign debt markets. (ECB Monthly Bulletin, June 2010)

Sovereign bond spreads relative to comparable German bonds widened considerably, especially for Greece (top panel of Figure 1). Ten-year sovereign bond spreads were at record highs and volatility in the bond markets increased very sharply. As a result, according to the ECB, liquidity conditions in the sovereign bond markets of several euro area countries deteriorated very sharply and liquidity almost completely dried up for Greece.

On May 10th (line 1), the ECB, with a view to restoring effective financial market functioning and thereby ensuring conditions necessary for the transmission of monetary policy, announced several new liquidity support programs. Chief amongst these programs was the intention to actively intervene in sovereign debt markets through the newly established Securities Markets Programme. These purchases are shown in the bottom panel of Figure 1. Notice that by July 2010, the ECB had all but stopped making sovereign bond purchases. This lull in purchases was also marked by a decline in sovereign spreads. At the time, this correspondence between the lower spreads, widely read as a reduction in tensions, and the timing of purchases was taken as ipso facto proof of the program's success. Indeed, a long period of relative calm ensued with the ECB making small purchases any time bond yields rose.

The relative calm evaporated with summer's heat. With further deterioration in Greece necessitating a bailout package (line 2), Euro-area government bond yields relative to comparable German bonds widened considerably. Tensions which had been somewhat confined to Greece, Ireland and Portugal spread increasingly to Italy and Spain. On 5 August ten-

\footnotetext{
${ }^{7}$ We thank Laurent Fransolet for kindly providing this data.
} 
European 10-Year Sovereign Spreads*

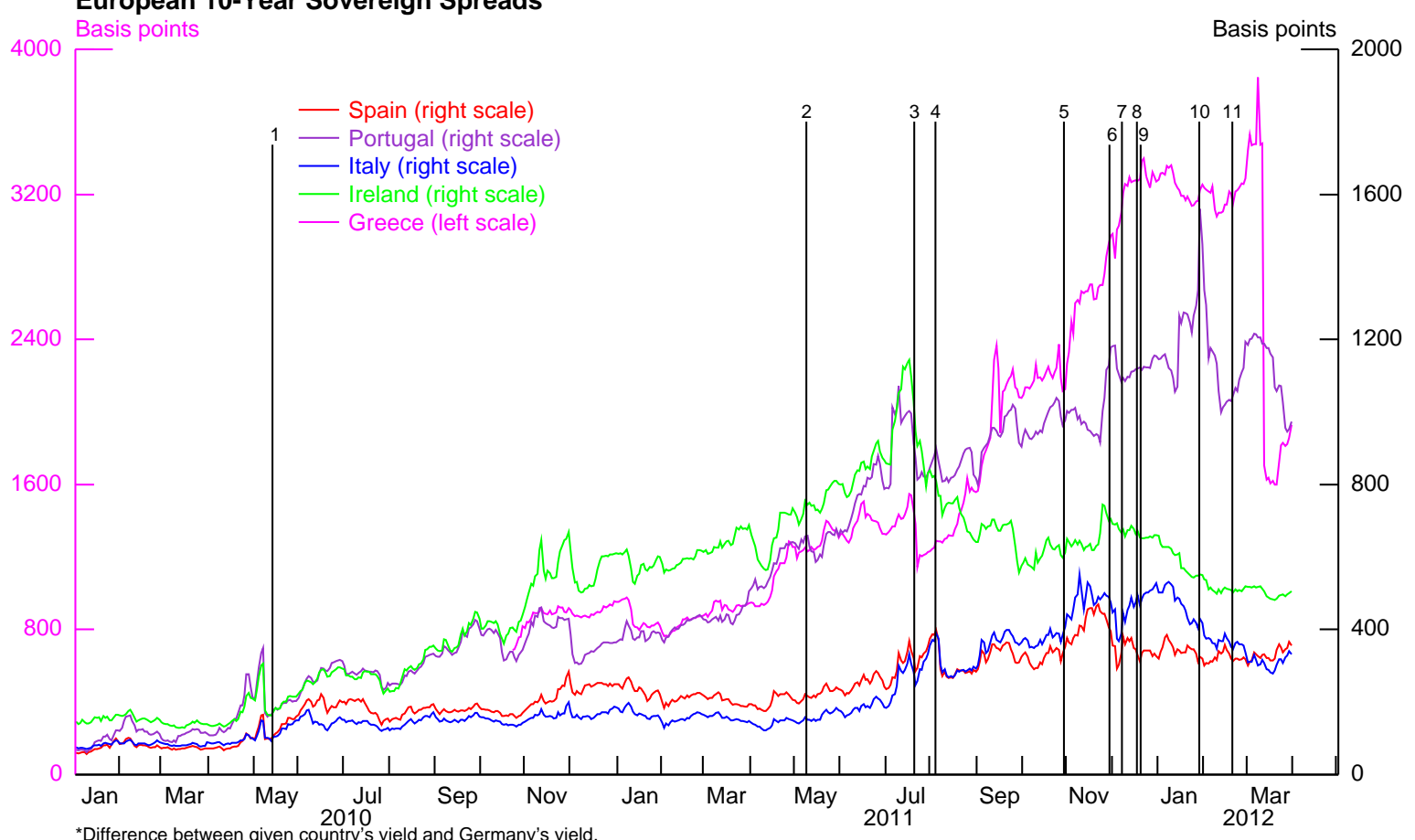

ECB SMP Weekly Purchases

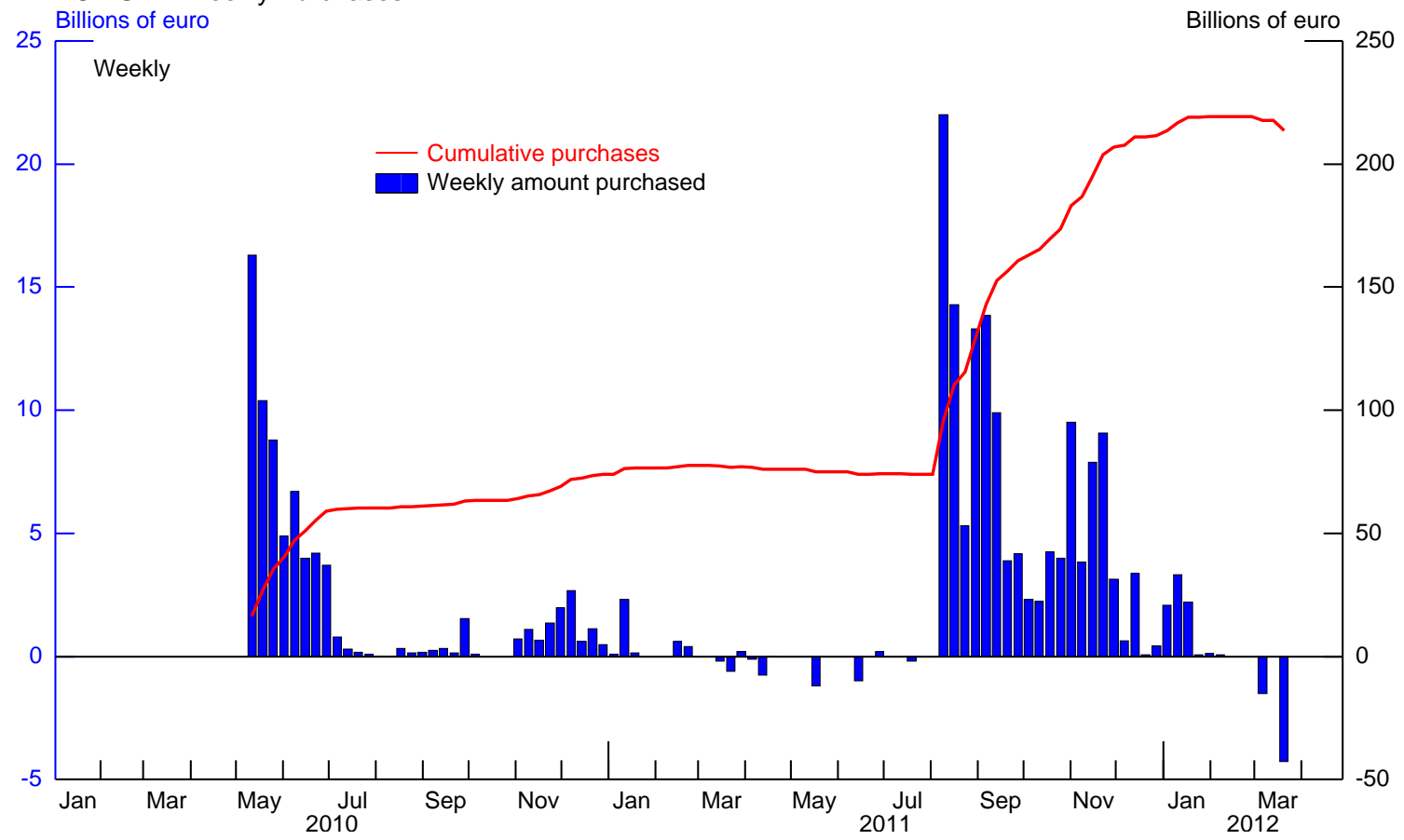

Figure 1: Sovereign Bond Spreads and Securities Markets Programme PurCHASES

Notes: The vertical lines in figure 1 denote key euro-area events: 1 . The announcement of the SMP; 2 . First Greek aid package; 3. July European Union leaders summit; 4. The expansion of the SMP to Italy and Spain; 5. October European Union leaders summit; 6 . The expansion of the swap line arrangement between the Federal Reserve and the ECB; 7. December 8th ECB meeting wherein they announced additional easing measures especially the longer-term refinancing operations (LTRO); $8 . \$ 150$ billion in IMF loans released to Greece; 9. The first LTRO; 10. January European Union leasers summit; and 11. The second three-year LTRO. 


\section{Purchases by Week}

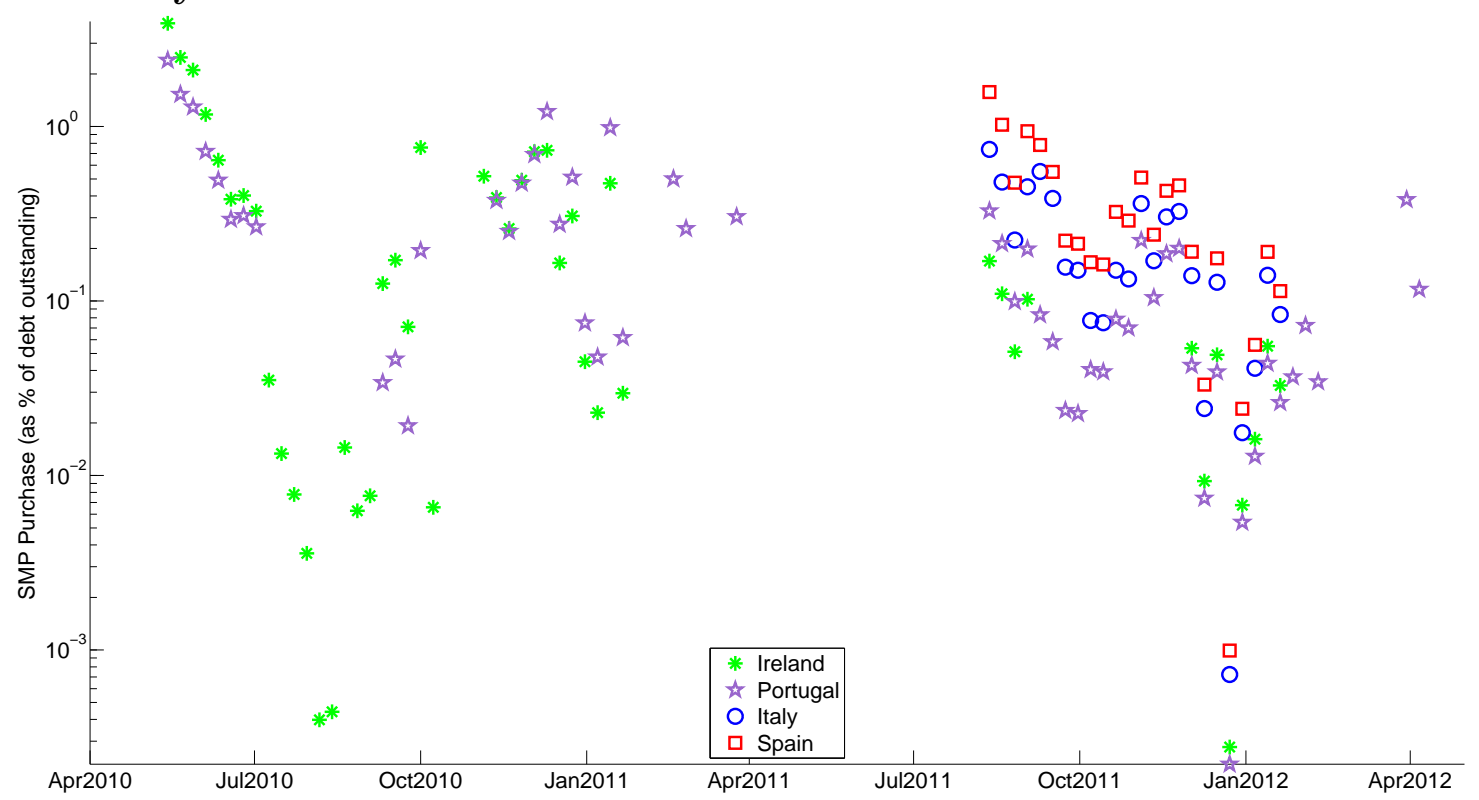

\section{Cumulative Purchases}

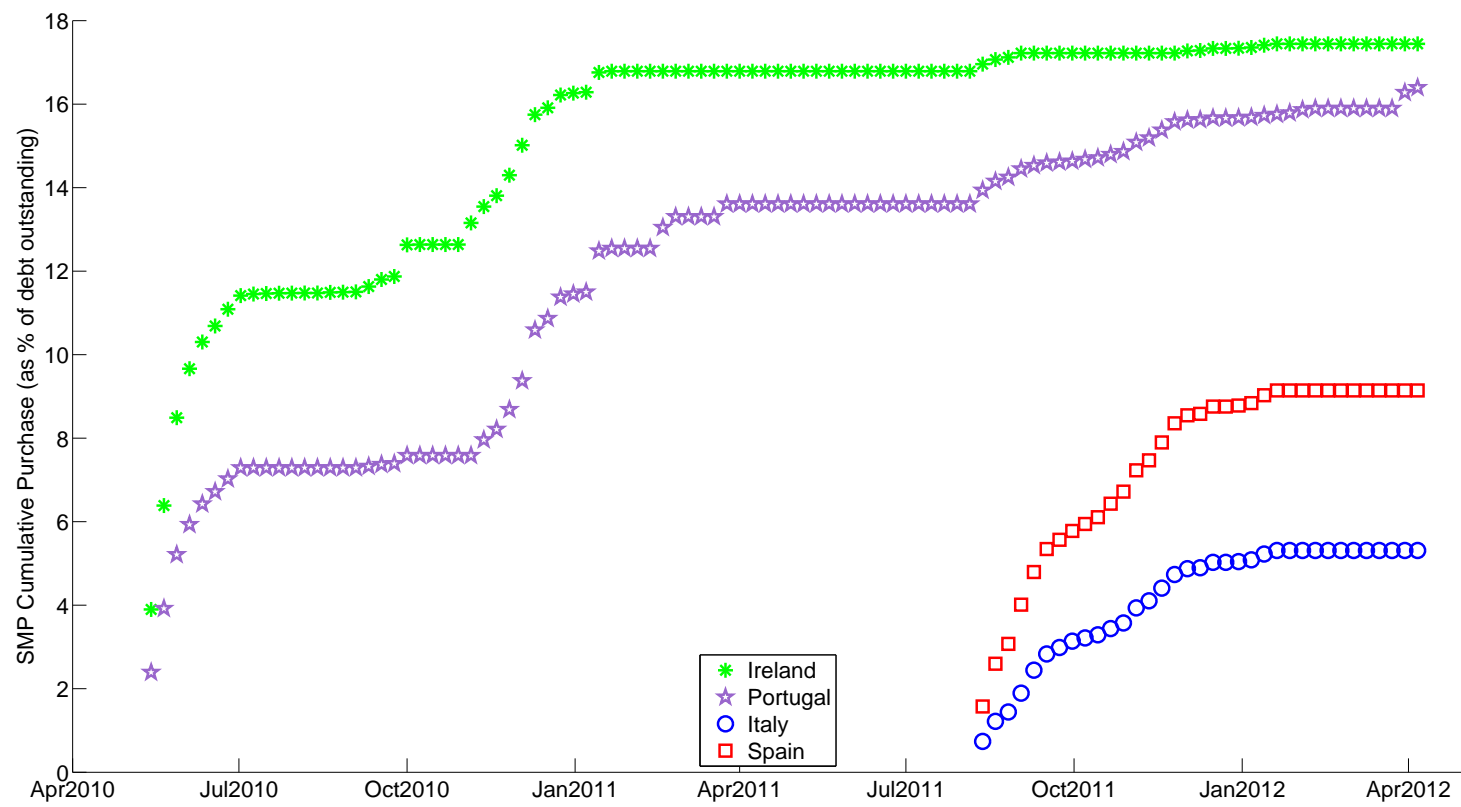

Figure 2: Securities Markets Programme Purchases, Country Estimates

year government bond spreads reached record highs in most euro area countries. Volatility reached a level last seen in the aftermath of the collapse of Lehman Brothers in September 2008. As a result, liquidity conditions in the sovereign bond markets of several euro area countries deteriorated very sharply. 
In response, the ECB expanded its purchase program to include the bonds of Italy and Spain (line 4). Figure 2 shows our estimates of the composition of purchases for the four countries we focus upon: Ireland, Portugal, Italy and Spain. With this expansion, intervention in Greece was over and the ECB focused on purchasing debt of the still viable peripheral economies.

The marked decline in sovereign spreads following this intervention is perhaps the most commonly cited evidence of the efficacy of the ECB's program. However, despite ongoing purchases, which dwarfed the earlier incarnation of the SMP, sovereign yields soon began to climb once again. This increase, that is the inability of the ECB to maintain a fixed level of yields in these markets, indicated to some commentators that the program was fundamentally ineffective. Further, that the long string of measures taken by European officials (lines 5 through 11) were needed because of this failure.

However, these criticisms miss the true intentions of the ECB. The ECB never intended to influence prices per se; they consistently stated that their interventions were aimed at improving market liquidity. The ECB always intended to allow market fundamentals drive the level of prices.

\section{Liquidity and Default}

Previous literature suggests that official bond purchases may have stock and flow effects. How exactly do these effects exist in an economic model? How can isolated periods of official purchases give rise to a permanent stock effect? What can we expect as the flow effect? Are there other factors that should be controlled for when looking for these effects in the data?

To this end we write down an asset-pricing model that gives an explicit explanation for liquidity risk: The risk that an agent cannot immediately sell an asset for the equilibrium price due to search frictions. Since a key feature of our bond and CDS data is variation in default probabilities over time, the model explicitly includes default. We then interpret official intervention as an exogenous reduction in the supply of bonds caused by the ECB's instantaneous purchases of bonds from agents wishing to sell. The model justifies the possible existence of a permanent stock effect and transient flow effects, as we explain below.

\section{$2.1 \quad$ Model}

Our search-based asset-pricing model adapts Duffie, Garleanu and Pedersen's (2005, 2007) which in turn rests on Peter A. Diamond's (1982) seminal work. Our development mirrors theirs except for the addition of an exogenous default arrival process. As in DGP (2007) we neglect the consideration of market-makers analyzed in DGP (2005). Our primary measure of liquidity is the difference between the equilibrium price and a frictionless price that would prevail if the asset were exchanged in Walrasian spot markets. We eventually connect this premium to the bond liquidity measures introduced in Section 1.

We set agents' time preference by a constant discount rate $r>0$ and assume they are risk-neutral - DGP (2007) show that this framework is a first-order approximation of a 
model with risk-averse agents and stochastic endowments. Investors are distinguished by whether or not she owns the asset and whether or not her intrinsic type is "high" or "low." A low-type investor experiences a holding cost of $\delta>0$ per time unit whereas a high-type investors has no such holding cost. DGP (2005) discuss several possible motivations for this construct. For these data we prefer a motivation tied to exogenous liquidity needs. For reasons exogenous to this particular asset market, the agent may need to liquidate her holdings to raise funds. Alternatively, the asset itself may become undesirable for factors we do not explicitly model, such as "headline risk" associated with certain sovereigns' debt.

A low-type investor switches to being high-type with intensity $\lambda_{u}>0$ while a high-type investor switches to being low-type with intensity $\lambda_{d}>0$, each as a result of an exogenous Poisson process. Therefore the four types of agent in the model are indexed by $\{h o, h n, l o, l n\}$ where $h$ denotes high-type, $l$ denotes low-type, $o$ indicates an asset owner and $n$ indicates an asset non-owner. By definition

$$
\mu_{h o}(t)+\mu_{h n}(t)+\mu_{l o}(t)+\mu_{l n}(t)=1, \forall t .
$$

The supply of the asset $s \in(0,1)$ is determined outside the model and restricts the mass of asset-owners,

$$
\mu_{h o}(t)+\mu_{l o}(t)=s, \forall t .
$$

The asset is infinitely-lived conditional on being in non-default, but we introduce into the model an exogenous default process with intensity $\lambda_{D} \geq 0$. Upon default the asset-market closes and owners receive the recovery value $R(t) \geq 0$.

According to an exogenous Poisson process with intensity $\lambda>0$ an investor meets another investor. The search is non-directed and therefore the other investor comes from a uniform distribution across the investor population. Reasonable parameterizations admit equilibrium transactions when low-type owners (lo) meet high-type non-owners $(h n)$ : lo investors wish to sell while the $h n$ investors wish to buy.

Assuming a law of large numbers applies (cf. Duffie and Sun (2007)) the rate of change of agents of different types is

$$
\begin{aligned}
\dot{\mu}_{l o}(t) & =-2 \lambda \mu_{h n}(t) \mu_{l o}(t)-\lambda_{u} \mu_{l o}(t)+\lambda_{d} \mu_{h o}(t) \\
\dot{\mu}_{h n}(t) & =-2 \lambda \mu_{h n}(t) \mu_{l o}(t)-\lambda_{d} \mu_{h n}(t)+\lambda_{u} \mu_{l n}(t) \\
\dot{\mu}_{h o}(t) & =2 \lambda \mu_{h n}(t) \mu_{l o}(t)-\lambda_{d} \mu_{h o}(t)+\lambda_{u} \mu_{l o}(t) \\
\dot{\mu}_{l n}(t) & =2 \lambda \mu_{h n}(t) \mu_{l o}(t)-\lambda_{u} \mu_{l n}(t)+\lambda_{d} \mu_{h n}(t) .
\end{aligned}
$$

These equations are identical to DGP's (2007) because the default process does not alter the evolution of agent types in the model. The intuition for, say, the first line is as follows.

\footnotetext{
${ }^{8}$ We maintain this assumption to remain directly comparable to DGP which eases the exposition. Ricardo Lagos and Guillaume Rocheteau (2009) generalize the model to allow for finitely many types and a continuous domain of possible holding amounts. They find that trade volume, bid-ask spreads and trading delays are affected by their richer set-up. Our analysis does not explicitly consider these features of the model, hence we opt for DGP's tractable framework and leave extension to Lagos and Rocheteau's framework to future research.
} 
With intensity $\lambda$ agents of type $l o$ meet other agents and $\mu_{h n}$ of them are $h n$ agents with whom $l o$ would like to transact. Meanwhile $l o$ is met by other agents with intensity $\lambda$ and $\mu_{h n}$ of them are again high-type non-owners with whom lo would like to transact. These meetings result in transactions that turn $l o$ agents into $l n$ agents. At the same time, there are exogenous entries into $l o$ from the $h o$ pool as well as exogenous exits from $l o$ into the $h o$ pool. The other lines follow similar explanations. DGP (2005) proves that there is a unique stable steady-state solution for this system.

The introduction of default affects the present value of the asset for every agent. Asset owners take account of the possibility of default and associated recovery rate, while nonowners take account of the possibility that they are never able to buy the asset. We put the value functions for each agent in the appendix and here present the first-order conditions obtained:

$$
\begin{aligned}
& \dot{V}_{l n}=r V_{l n}-\lambda_{u}\left(V_{h n}-V_{l n}\right)+\lambda_{D} V_{l n} \\
& \dot{V}_{h o}=r V_{h o}-\lambda_{d}\left(V_{l o}-V_{h o}\right)-\lambda_{D}\left(R-V_{h o}\right)-1 \\
& \dot{V}_{h n}=r V_{h n}-\lambda_{d}\left(V_{l n}-V_{h n}\right)-2 \lambda \mu_{l o}\left(V_{h o}-P-V_{h n}\right)+\lambda_{D} V_{h n} \\
& \dot{V}_{l o}=r V_{l o}-\lambda_{u}\left(V_{l n}-V_{l o}\right)-2 \lambda \mu_{h n}\left(V_{l n}+P-V_{l o}\right)-\lambda_{D}\left(R-V_{l o}\right)
\end{aligned}
$$

We have subsumed the dependence on $t$ of $\dot{V}_{(\cdot)}, V_{(\cdot)}(t), \mu_{(\cdot)}(t)$ and $R(t)$. These equations reduce to DGP's (2007) when $\lambda_{D}=0$. For price determination we use the surplus-splitting rule

$$
P=(1-q)\left(V_{l o}-V_{l n}\right)+q\left(V_{h o}-V_{h n}\right)
$$

where $q \in[0,1] .^{9}$

Our analytical focus is on assets whose market value increases as search frictions decrease. $^{10}$ To ensure this intuitive feature of the model, we adopt DGP's (2005) condition 1. Furthermore, we are interested in situations where the present value of the default-free asset's cash flow is greater than the recovery value obtained upon default. Therefore we maintain the following assumption:

Assumption 1 The asset supply and switching intensities are such that

$$
s<\frac{\lambda_{u}}{\lambda_{u}+\lambda_{d}} \quad \text { and } \quad R=\frac{\zeta}{r} \text { for } \zeta \in(0,1) .
$$

The first part of Assumption 1 ensures that in steady state there is less than one unit of asset per high-type agent, and therefore the asset's discounted cash flow equals the frictionless price defined below. The second part of the assumption implies that the recovery rate is lower than the present value of the asset's cash flow conditional on it being default-free. Although the following propositions can be modified to condition on whether or not Assumption 1 holds, this distracts from the main analysis and so we abstract from it. Our first result is an expression for the equilibrium asset price.

\footnotetext{
${ }^{9}$ DGP (2007) discuss how this rule can emerge from various bargaining setups, notably Nash-bargaining.

${ }^{10}$ DGP (2007) note that an asset, for instance U.S. Treasuries, might experience a "scarcity value" instead of a liquidity risk premium.
} 
Proposition 1 For any given initial distribution $\mu(0)$ there exists an unique steady-state equilibrium. The price is given by

$$
P=\frac{1+R \lambda_{D}}{r+\lambda_{D}}-\frac{\delta}{r+\lambda_{D}} \frac{r(1-q)+\lambda_{d}+2 \lambda \mu_{l o}(1-q)+(1-q) \lambda_{D}}{r+\lambda_{d}+\lambda_{u}+2 \lambda \mu_{l o}(1-q)+2 \lambda \mu_{h n} q+\lambda_{D}} .
$$

Proof: See the appendix.

As noted, default risk does not affect the steady-state distribution of agent types. Hence, when $\lambda_{D}=0$ equation 7 reduces to DGP's (2007) price which we call the default-free price $P_{d f}$.

The equilibrium price naturally separates into two pieces:

$$
\begin{aligned}
P & =\text { Frictionless price }- \text { Cost of liquidity risk } \\
& =P_{f}-P_{f} L
\end{aligned}
$$

Note from (7) that both of these are functions of $\lambda_{D}$. The first term represents the present value of the asset's cash flow, taking into account the possibility of default, which we call the frictionless price $P_{f}$. The second part of Assumption 1 ensures that the default-free frictionless price (i.e. when $\lambda_{D}=0$ ) is greater than any other price for any configuration of the parameters. The point of the model is to analyze the costs of default and liquidity risks and Assumption 1 ensures that both costs are always nonnegative. Note that the default-free frictionless price is $1 / r$.

The second term represents the cost of search frictions as dictated by the liquidity premium:

$$
L=\frac{P_{f}-P}{P_{f}}=\frac{\delta}{1+R \lambda_{D}} \frac{r(1-q)+\lambda_{d}+2 \lambda \mu_{l o}(1-q)+(1-q) \lambda_{D}}{r+\lambda_{d}+\lambda_{u}+2 \lambda \mu_{l o}(1-q)+2 \lambda \mu_{h n} q+\lambda_{D}}
$$

This premium expresses the cost of search frictions as a proportion of the frictionless price. These are the correct units for the premium because the frictionless price is the asset value when there is no liquidity risk. For instance, if the liquidity premium $L=0.1$ we say that agents must be compensated in order to hold the asset's liquidity risk, and this risk weighs down on the price by $10 \%$.

The following proposition describes properties of the frictionless price, price and liquidity premium that are used in the rest of the paper.

Proposition 2 Let $\bar{\lambda}_{D}$ be some a constant depending on model parameters other than $\lambda_{D}$. Let Assumption 1 hold. The frictionless price $P_{f}$ is

1. unchanged as s varies

2. decreasing in $\lambda_{D}$ such that $P_{f} \underset{\lambda_{D} \rightarrow 0}{\longrightarrow} 1 / r$ and $P_{f} \underset{\lambda_{D} \rightarrow \infty}{\longrightarrow} R$

The liquidity premium $L$ is 


\section{3. increasing in $s$}

The price $P$ is
5. decreasing in $s$

5.
4. decreasing in $\lambda_{D}$ for all $\lambda_{D} \geq \bar{\lambda}_{D}$

such that $L \underset{\lambda_{D} \rightarrow \infty}{\longrightarrow} 0$
6. such that $P \underset{\lambda_{D} \rightarrow 0}{\longrightarrow} P_{d f}$
and $P \underset{\lambda_{D} \rightarrow \infty}{\longrightarrow} R$

The effects of $\lambda_{D}$ on $L$ and $P_{f}$ hold even when $\lambda$ is a bounded function of $\lambda_{D}$. The condition $\frac{\lambda_{d}}{1-q}+\lambda \mu_{l o}>\left(\frac{1}{\zeta}-1\right) r$ is sufficient for $L$ to be everywhere decreasing in $\lambda_{D}$.

Proof: See the appendix.

Part 1 is clear from the definition of $P_{f}$ and intuitively obvious. ${ }^{11}$ Part 2 is obvious from the definition of $P_{f}$ and intuitively reflects how that probability of default and recovery value enter into the frictionless price for the asset. Our Assumption 1 ensures that $P_{f}$ monotonically decreases towards $R$ as $\lambda_{D}$ increases.

An important part of the proposition is part 3. ${ }^{12}$ This effect captures the intuition that increases in the supply of bonds rest more and more in the hands of low-type agents. This increases the compensation agents demand for the increased risk that they fall in this undesirable situation. Conversely, a reduction in supply limits the steady-state mass of these agents desperate to sell, meaning that search frictions bear less on the present value of the asset and the liquidity premium falls. Our interpretation of a stock effect of ECB purchases is a reduction in $s$. Therefore Proposition 2 predicts that ECB purchases decrease bonds' liquidity premium.

Part 4 is intuitive. The cost of liquidity in this model stems from a risk that an assetowner might be unable to sell the asset when they want to in the future: As the asset's default becomes increasingly likely, the "future" shrinks over which the asset-owner reckons the liquidity risk and hence the premium falls. The data exhibit great variance over time and cross-sectionally in this variable. Therefore our theory implies that controlling for the evolution of default risk is important to our empirical exercise. Moreover, one sees that the default intensity enters $P_{f}$ and $L$ separately - therefore it is possible for default risk to systematically affect bond prices (via their liquidity premium) apart from the discounting channel at play in $P_{f}$. This is important to keep in mind when we difference bond and CDS prices. It is natural to assume that these prices contain the identical frictionless price for all values of the default intensity. However their respective liquidity conditions can systematically differ as a function of the default risk. Therefore the difference between these two asset prices can still systematically respond to default risk through their relative liquidity premia.

The last part of the proposition provides a sufficient condition allowing $\lambda_{D}$ 's effect on $L$ and $P$ to be pinned down. While a bit esoteric, this condition is widely satisfied and fails

\footnotetext{
${ }^{11}$ The behavior of $P_{f}, L, P$ in response to changes to the other parameters of the model $\delta, \lambda, \lambda_{u}, \lambda_{d}$ are immaterial to our analysis. As such, we leave these results available from the authors upon request.

${ }^{12}$ This is equivalent to DGP's (2007) first proposition result for the effect of $s$ on the price.
} 


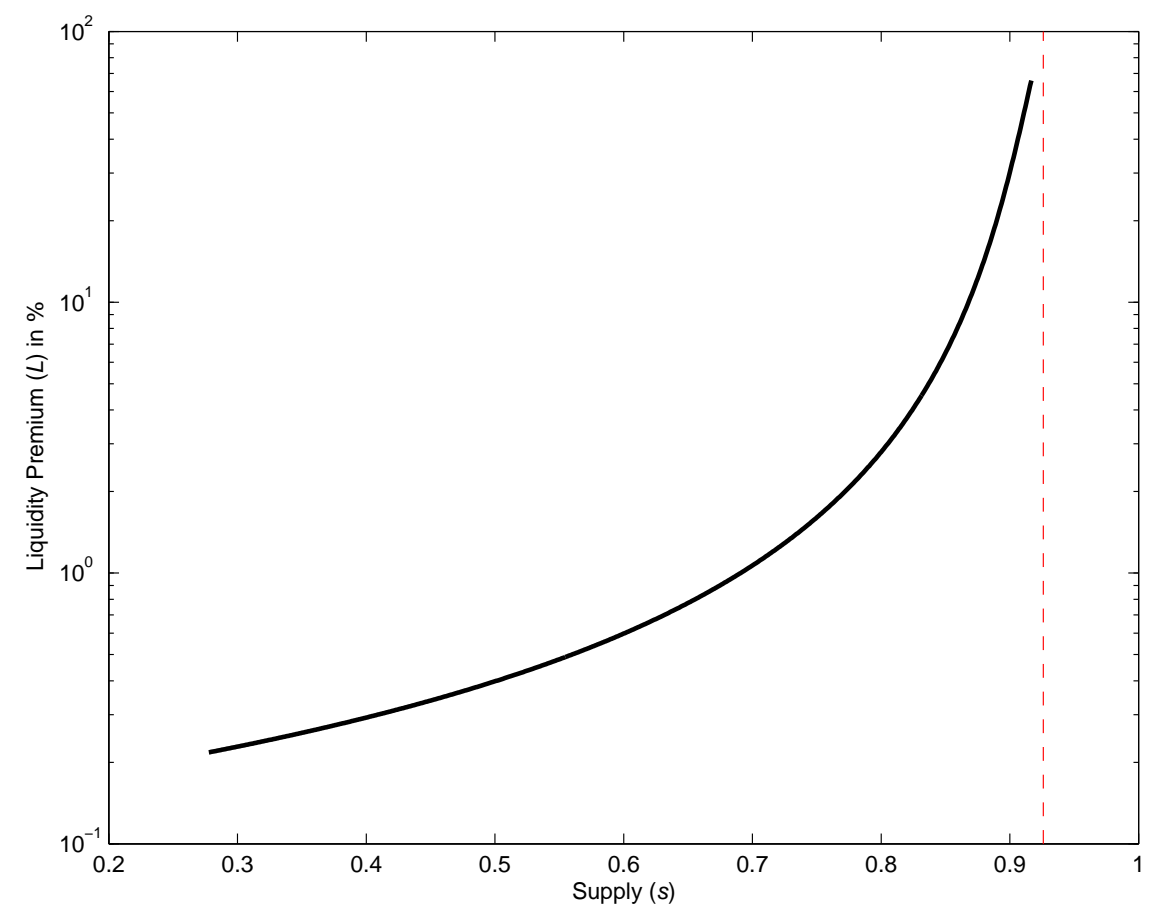

Figure 3: Steady-State Liquidity Effects of Supply

to hold basically only in pathological parameterizations of the model. Therefore we take its satisfaction as given so that the model clearly predicts that the asset's liquidity premium falls as $\lambda_{D}$ rises. $^{13}$

We now illustrate how these steady-state behaviors work in simulations.

Figure 3 demonstrates the effect of supply on the steady-state liquidity premium. ${ }^{14}$ The vertical red dashed line indicates $\frac{\lambda_{u}}{\lambda_{u}+\lambda_{d}}$ for our calibration. Recall that we will interpret ECB purchases as a decrease in $s$. We see that the supply effect can be sizeable, and is marginally diminishing. For a large initial supply the liquidity effect of ECB purchases is larger than for a small initial supply. This reflects that at a low supply the steady-state mass of lo agents wanting to sell is minuscule and therefore the liquidity premium is small to begin with.

Figure 4 demonstrates the effect of default risk on the steady-state liquidity premium and price. We see that the default risk effect can be sizeable, noting that it is the logged default intensity that gives rise to, roughly speaking, linear effects on the liquidity premium. The price effects of default risk come through both $L$ and $P_{f}$ since they are independently affected by $\lambda_{D}$. The price is falling over most of the default intensity's range. ${ }^{15}$ The liquidity premium is everywhere decreasing in the default intensity.

\footnotetext{
${ }^{13}$ The appendix provides arguments on why this condition is satisfied by parameterizations of interest.

${ }^{14}$ Since $P_{f}$ is unaffected by $s$, the effects on price come solely through this liquidity effect.

${ }^{15} \mathrm{But}$ it is possible for the price to actually rise as $\lambda_{D}$ gets large. In fact, though difficult to see visually, the minimum price in Figure 4 is below the recovery value (8) for a $\lambda_{D}$ to the left of where the plot ends. This means that the model is capable of predicting positive expected returns for bonds that are close to default, a feature we do not explore further in this paper.
} 

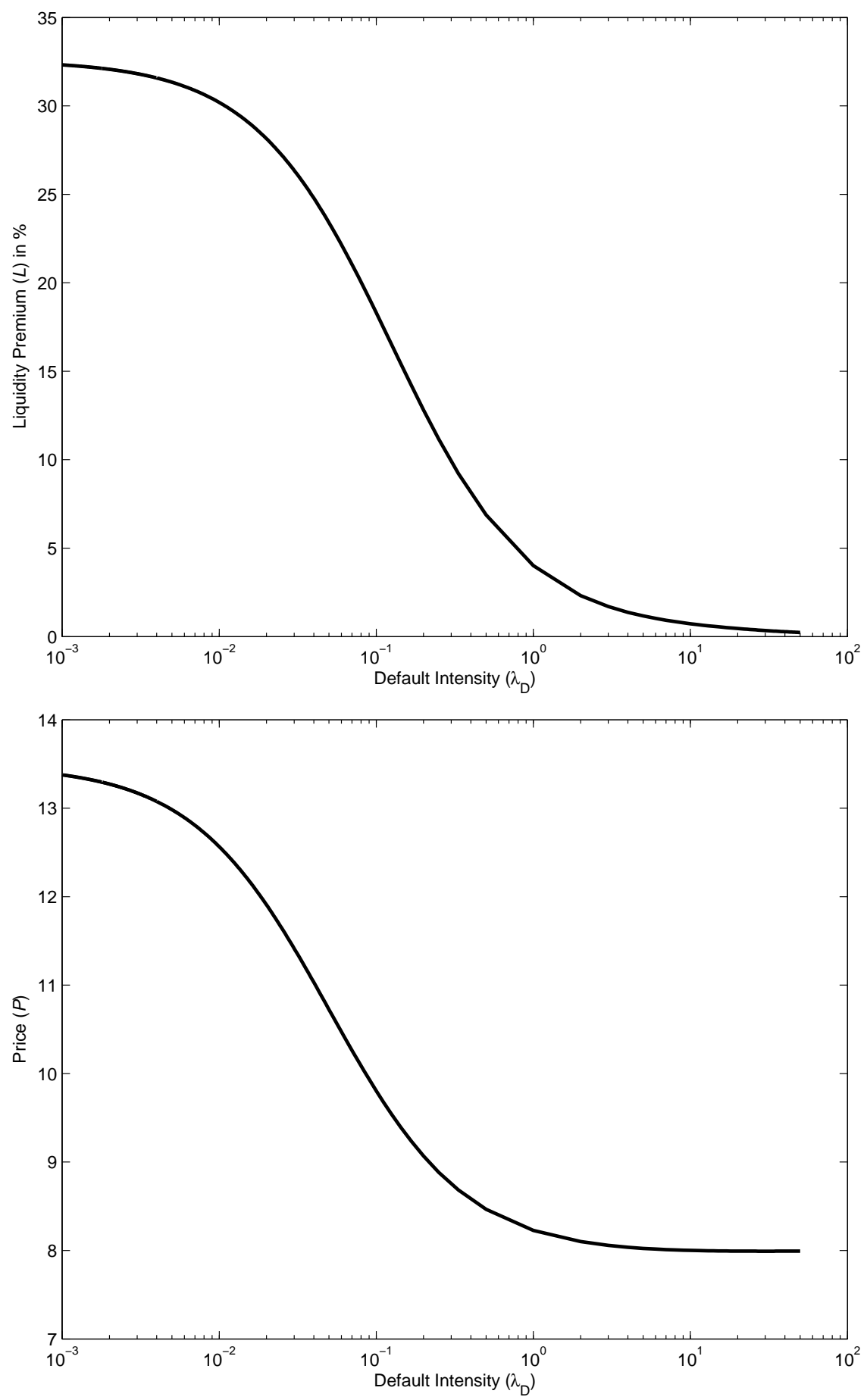

Figure 4: Steady-State Liquidity and Price Effects of Default

We now consider out-of-steady-state dynamics of the model in an attempt to give an economic rationale for what flow effects there might be to ECB purchases. In these experiments we interpret ECB purchases as taking bonds immediately out of the hands of low-type bond holders who are looking to sell. The ECB's intervention is able to cut through the search 
5 basis points

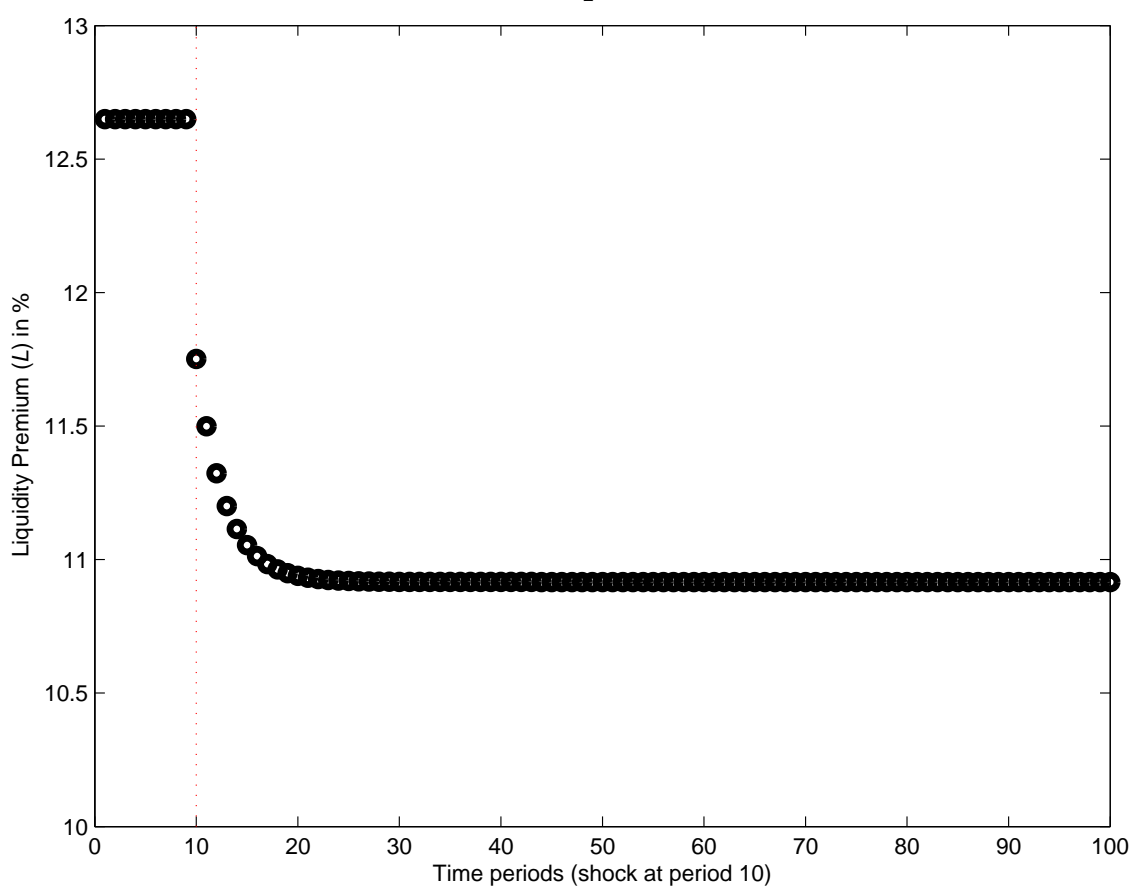

15 basis points

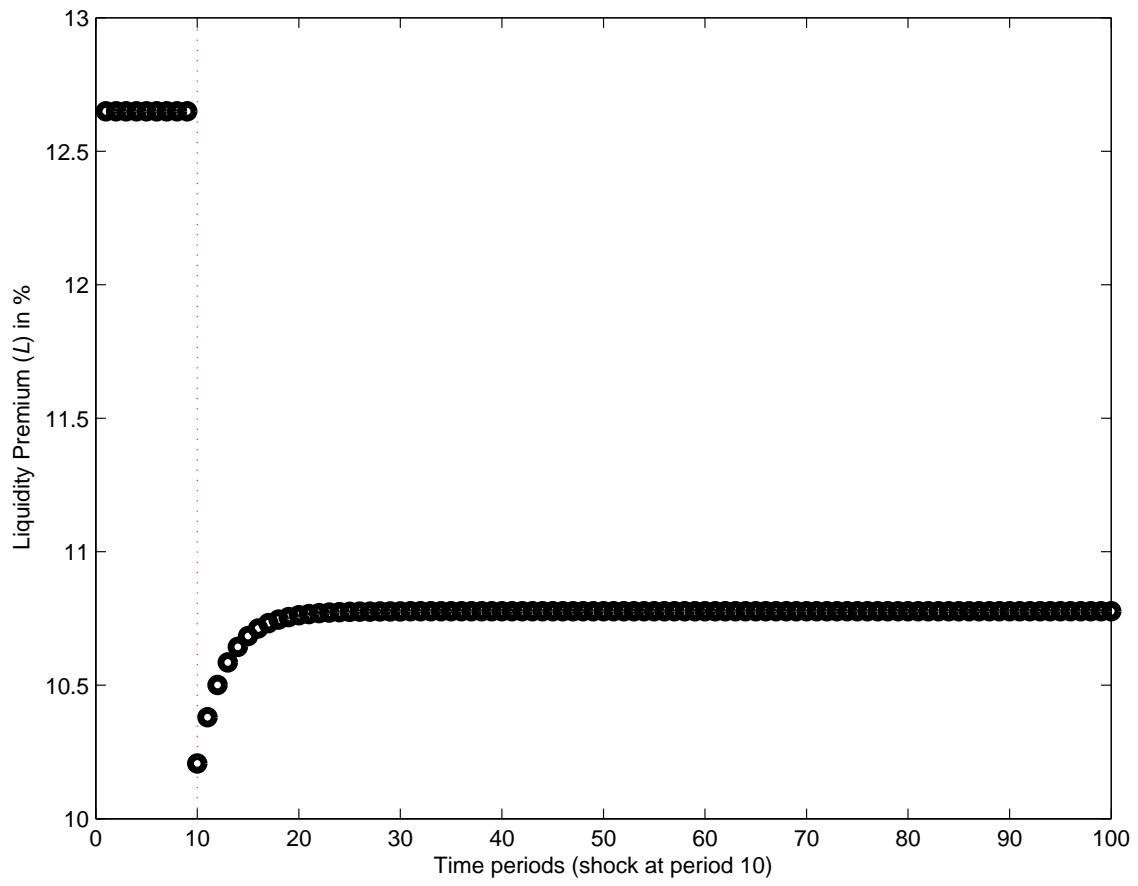

Figure 5: Liquidity EFFECTS of lo-SHOCK

frictions inherent to the over-the-counter market and buy bonds from those desperate to sell. Therefore we imagine ECB purchases' flow effect being a "lo-shock" wherein $\mu_{l_{o}}$ is instantaneously reduced and the corresponding bonds taken out of the system. This shock 
is not purely transient since it affects $s$ and hence the model's steady-state, but we use it as our device to understand what flow effects ECB purchases may have.

Figure 5 shows two sets of results: One where the lo-shock amounts to 5 basis points, the other where the $l o$-shock amounts to 15 basis points, of the total outstanding supply of bonds. ${ }^{16}$ Consistent with Figure 3 and the fact that the two purchase amounts are very close in size, their permanent effects are quite similar so that liquidity premium ends up approximately the same steady-state in either case. But how liquidity arrives at its new steady-state is quite different across cases. The 5 basis point purchase is followed by a fall in the liquidity premium towards its new long-run level. By contrast the 15 basis point purchase improves liquidity more than is sustainable in the long-run, and therefore the liquidity premium rises towards the steady-state after the lo-shock. These are quite different transition paths for quite similar levels of intervention, each roughly the magnitude of ECB's initial SMP purchases (recall Figure 2).

Furthermore, it is possible for the $l o$-shock to be just the right size (here, between 5 and 15 basis points) so that the liquidity premium jumps exactly to its new long-run value, in which case there is no flow effect at all. Quite intuitively, it can be shown that for any parametrization of the model there is a lo-shock that immediately shifts prices to the new steady state with no transition dynamics and thus no flow effects.

We now complete the link between our theoretical model and Section 1's evidence on implied default probabilities and the CDS basis. We use the model to represent the behavior of investors in sovereign debt who eat coupon payments and reinvest face value payments back into new sovereign bonds. Therefore the model makes predictions on how bond liquidity varies as a function of default intensity and bond supply, among other things. On the other hand we have not explicitly modeled CDS. Thus we make a key identifying assumption: CDS liquidity premiums do not vary in response to the bond market factors we have explicitly modeled. This assumption is made formal in Section 3.1 so that possible econometric issues are brought into focus. We argue that our identifying assumption is realistic because search frictions for CDS are unlikely to vary systematically over the life of a bond. To see why, note that when a bond first enters the secondary market, institutional buyers usually take out CDS protection. Whereas search is required if the bond-holder later wants to sell their bond, "selling" CDS takes the form of cash settlement of their existing protection - no search is required because this occurs with the CDS-protection-seller with whom the bond-holder has the CDS contract.

Letting the CDS liquidity premium be written $\tilde{L}$, we have that the difference between $\mathrm{CDS}$ and bond liquidity is

$$
B=L-\tilde{L}
$$

Our primary measure for $B$ comes from the difference in bond- and CDS-implied default probabilities, converted to yield space for interpretability. The reader might recognize $B$ as ( -1 times) a modified version of the common CDS basis. The modification comes from using asset prices at many maturities within a term structure model to calculate a more accurate

\footnotetext{
${ }^{16}$ That is, if the initial $s$ were 0.9 , then these $l o$-shocks take away 0.00045 or 0.00135 bonds out of the hands of lo agents, respectively.
} 
measure for $B$ than any one maturity's prices provides - see the appendix for details.

Therefore we interpret systematic fluctuations in $B$ as reflecting variation in bonds' liquidity premium. A decrease in the bond liquidity premium $L$ causes $B$ to decrease. Hence our model makes the following predictions which we bring to the data:

1. $B$ is decreasing in the default intensity

2. $B$ is permanently decreasing in SMP purchases

3. The flow effect of $l o$-shocks on $B$ is undetermined

The first two predictions are clear from the model since they derive from algebraic analysis of its steady state. The third prediction concerns out-of-steady-state features of the model which are visible in the simulation evidence plotted above.

\subsection{Official Intervention}

To express our main research inquiry, we must answer the following: How do we represent the European Central Bank's Securities Markets Programme? Throughout Section 2 we have touched on our answer. Here we address it directly and provide three reasons for our modeling choice.

First, the ECB's objective function is not that of the representative investor's. The central bank optimizes different criteria and is not subject to the liquidity pressures we have represented by low-type and high-type investors. Therefore we regard SMP purchases as exogenous to the model, not undertaken for profit motives as captured by our investors' first-order conditions (4). Second, the ECB is evidently a buy-and-hold investor. This is an elaboration on our first point. Furthermore it suggests the particular manner in which official intervention should be modeled: An exogenous reduction in the supply $s$ of bonds that are available for private market transactions. Third, we assume that the ECB's buying is special - there is no searching required for its purchases. The institution is large, visible and can buy as many bonds as it wishes from the low-type bond sellers. Therefore we model ECB purchases as lo-shocks .

Two aspects of this modeling choice are noteworthy. The first was discussed above: Officials may wish to avoid transition dynamics to avoid inducing market volatility. If this is the case, then moving prices to a new steady-state most likely requires several successive interventions of targeted size. The second aspect is more nuanced and stems from the knowledge that steady-state values of $\mu_{l o}$ can be small. ${ }^{17}$ If the ECB can buy only from asset owners who wish to sell (i.e. agents in $\mu_{l o}$ ), then there is a maximum amount of bonds that can be purchased at any one time. If the ECB bought out every lo agent, it still might not have moved supply to where it ultimately wanted steady-state prices to rest. If so, the ECB would need to wait for $\mu_{l o}$ to "fill up" with agents intrinsically dropping out of $\mu_{h o}$.

\footnotetext{
${ }^{17}$ For example, in their benchmark simulations DGP (2007) analyze the steady-state values of $\mu_{l o}$ of 0.0028 and 0.004 .
} 
This constraint could be another reason why official purchases might need to be successive in order to move long-run prices to the ECB's desired level.

Since the data show (Figures 1 and 2) that ECB purchases have indeed been successive, it is attractive that our model suggests a few reasons for why this could be the case. Moreover, these considerations are important to remember when we report finding a significant stock effect, as we discuss below.

\section{Results}

This section describes the maximum likelihood procedure used to fit Section 2's model to Section 1's evidence. The linear specification benefits from simplicity and approximately expresses the structure dictated by our theory. Our estimation procedure reduces down to least squares estimation. The results support the predictions of our model and show a robust stock effect of official bond purchases.

Our results are calculated with the following questions in mind:

1. Are the data consistent with a stock effect of ECB purchases (the liquidity premium effect of changing $s$ brought about by a lo-shock)?

2. Is there a clear flow effect of ECB purchases (the transient effects on liquidity of the model's transition to a new steady state after a lo-shock)?

3. Are these effects robust to including appropriate control variables?

\subsection{Specification}

To answer our main questions we use feasible generalized least squares to match the asset-pricing framework to the data. Our benchmark dependent variable is the difference between bond- and CDS-implied default probabilities discussed in Section 1, which under our identifying assumption represents systematic variation in the bond liquidity premium. The weekly-frequency estimates of SMP purchases discussed in Section 1 measure the ECB's official intervention. We use CDS-implied default probabilities to measure a bond's probability of default.

With our panel data we estimate the equation

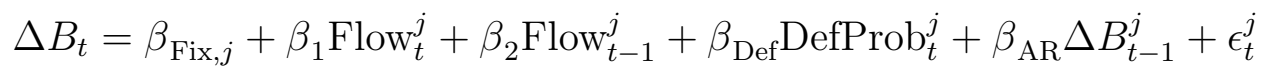

We index nations by the superscript $j . B_{t}^{j}$ is the relative liquidity and comes either from our more default probability difference measure constructed from the term structure of bonds, described at length in the appendix. Flow $_{t}^{j}$ is the SMP purchase in week $t$ converted to a proportion of the amount of country $j$ bonds outstanding - we include the contemporaneous and lagged effect, which enables us to distinguish temporary and permanent effects. ${ }^{18}$

\footnotetext{
${ }^{18}$ Additional lags were found to be insignificant.
} 
$\operatorname{DefProb}_{t}^{j}$ is the default probability for country $j$ as derived from CDS premia. We estimate the equation in first differences due to possible nonstationarity for some countries. Both time-series and cross-sectional variation estimate the coefficients on these terms because these are identical across $j$. Country fixed-effects are estimated by the $\beta_{\text {Fix,j }}$.

We include DefProb which is approximately equal to the log of the default intensity $\lambda_{D}$. This is included because Proposition 2 implies that bond liquidity is increasing in default intensity and from our simulations we saw that its effects are roughly log-linear. It is noteworthy that previous empirical studies on the effects of official bond purchases have not included this variable, for a couple of good reasons. One: The periods or countries on which the previous research focuses often include little variation in conventional measures of this variable, and therefore its effects may have been negligible. Two: Without a structural model to rely upon, one might reasonably assume that subtracting bond price from CDS price cancels out the default probability. Indeed, the frictionless part of their prices contain the identical term discounting the present value of cash flows using the default probability. However, our model highlights that there remains in the residual a relative liquidity term which systematically varies along with the matching situation in either market.

We also include the past change in bond liquidity. The first reason we include this control is the fact that our model is a rough depiction of reality, particularly in its assumption of a continuum of agents involved in the market. If a law of large numbers for these masses is only approximate (due to the finite number of market participants), there can be exogenous fluctuations in the proportions of different agents around the steady-state values. We want to control for these fluctuations that are due to reasons other than official intervention. The second reason to control for the past change in bond liquidity is due to the basic econometric problem of estimating a treatment effect. When doing so, one should consider the following: It could be that bond liquidity itself is a signal used by the ECB to conduct bond purchases in the first place. The intervention might be "timed" such that the liquidity after the intervention on average is better, even if there are no effects of the purchases themselves. The intervention could represent just a statement that "This is the worst liquidity we've seen in the bond market" with no direct market effect, and bond liquidity improves on average after it reaches a new low. If this is the case, we'd expect $\beta_{\mathrm{AR}}$ to be negative and drive out any significance of SMP flow if the latter did not independent affect bond liquidity but only responded to poor liquidity conditions itself.

Finally, consider the nature of our $\epsilon_{t}^{j}$ error terms. Two of their likely features stand out. First, bond liquidity conditions have varied greatly across the countries we consider. The notable swings for Portugal, Ireland, Italy and Spain have not occurred in France. While our explanatory variables soak up some of these differences, our residuals may still be notably different across countries. Therefore we should control for the average size of each country's error terms in order to prevent scaling differences from driving the panel results towards the time series variation of the country with the largest residual variation. Second, the unmodeled variation in bond liquidity could very well be contemporaneously correlated across countries. The exogenous factors affecting Spain's bond market may also affect Italy's.

For these reasons we use generalized least squares (GLS) for our main results. We consistently estimate the errors' covariance by the residuals from a first-step ordinary least squares 
Table 1: Estimation Results

\begin{tabular}{rrrrrrr}
\hline \hline$\beta_{1}$ & $\beta_{2}$ & $\beta_{\text {Def }}$ & $\beta_{\mathrm{AR}}$ & $N$ & $R^{2}$ & $\begin{array}{c}\beta_{1}=\beta_{2} \\
F \text {-statistic }\end{array}$ \\
\hline-19.41 & 14.77 & -3.50 & -0.06 & 464 & 0.441 & 109.42 \\
1.92 & 2.28 & 0.28 & 0.05 & & & $<0.0001$ \\
$(-10.09)$ & $(6.49)$ & $(-12.35)$ & $(-1.25)$ & & & \\
\hline \hline
\end{tabular}

Notes: Weekly data for January 2010 through April 2012, for Ireland, Portugal, Italy and Spain. Coefficients $\beta_{1}, \beta_{2}$ and $\beta_{\text {Def }}$ give basis point response to percentage point change. Generalized least squares with country fixed-effects. Heteroskedasticity robust standard errors in italics underneath point estimates and $t$-statistics in parenthesis underneath. $p$-value from $\chi(1)$ in italics under $F$-stat.

(OLS) estimation. Given our model this should result in more efficient estimates. The residuals exhibit negligible autocorrelation and so we report White (1980) standard errors and $t$-statistics. The appendix reports results for simple OLS, which are qualitatively similar.

\subsection{Discussion}

Table 1 reports our benchmark results. These use data from January 2010 through April 2012 for Ireland, Portugal, Italy and Spain, taken from the five-year maturity. ${ }^{19}$ We focus on the five-year maturity because market participants report that official purchases were heaviest around this tenor, five-year sovereign CDS are liquidly traded, and it roughly captures the maturity preference of ECB purchases as revealed by the Greek debt restructuring (see the appendix).

The estimates of $\beta_{1}$ and $\beta_{2}$ give our main finding. From the highly significant estimate for $\beta_{1}$, we find a 19.4 basis point impact decline of the liquidity premium to a purchase of one percent of debt outstanding. From the estimate for $\beta_{2}$, we find that 14.8 basis points of this impact effect is temporary. The permanent effect is therefore 4.6 basis points per percentage point purchased, which the $F$-statistic of 109 says is highly significant. ${ }^{20}$ These estimated temporary and permanent effects correspond to our model's flow and stock effects, respectively.

The stock effect theoretically reflects the fact that ECB purchases permanently reduce the steady-state mass of agents who are stuck with the bond when they wish to sell. In the model it is possible to sharply drive down the bond liquidity premium temporarily by depleting the pool of sellers. We indeed find that the impact effect of ECB purchases is sizeable. Thereafter, the liquidity effects moderate to a long-lasting and modest effect on soveriegn bond markets.

\footnotetext{
${ }^{19}$ We exclude Greece from our benchmark results because its particularly dire situation (it defaulted in February 2012, and was expected to several months prior) leads its price data to be unreliable near the end of our sample.

${ }^{20} \mathrm{Of}$ course, the further hypothesis $\beta_{1}=\beta_{2}=0$ is even more strongly rejected.
} 
Furthermore, we find a significant negative estimate for $\beta_{\text {Def }}$, as suggested by our model. For a one percentage point increase in the country's default probability, the liquidity premium falls 3.5 basis points. Previous studies often have excluded this variable from investigation. Nevertheless our theory states that it holds a systematic role for bond liquidity and we find support for this in the data.

It is notable that $\beta_{\text {Def }}$ is found to be significantly negative. Our theory abstracts from many possible realistic features of bond markets, including the idea that increasing default risk is associated with market dysfunction that would serve to increase bond liquidity premia. Recently, He and Milbradt (2012) model corporate bonds by combining a search-based liquidity mechanism with an endogenous default decision by firm owners, and their theory predicts that the liquidity premium is increasing in default probability. The reason they arrive at the contrary prediction lies in their assumption that the recovery value upon default is not immediately paid. Therefore, default forces bondholders to hold onto their bonds, in a possibly more illiquid market, until an uncertain future court decision gives them payment. That feature of their model is motivated by situations such as the Lehman Brothers collapse, where creditors waited several years for payment - in contrast, we assume that the sovereign bond's recovery value is given to bondholders immediately, as was approximately the case for the Greek debt restructuring of 2012.

The empirical challenge was two-fold. One: That we have measures of bond liquidity that are as efficient (noise-free) as possible. We provide these via the term structure machinery, described in Appendix 1. Two: That the data are approximated by a parametrization of the model wherein bond supply changes of the SMP's magnitude can have noticeable effects on the bond liquidity premium. This is evidently the case in our data, and we refine our estimate by including important controls for other drivers of bond liquidity conditions as suggested by our theory.

Altogether our estimates say that ECB intervention had a significant effect on bond market liquidity. Our empirical results benefit from the panel nature of our data set and the fact that European sovereigns have reasonably deep CDS markets that enable us to get a good read on sovereign bonds' relative liquidity conditions. The interpretation of our estimates is aided by our theoretical model which describes a clear channel through which official purchases can have a temporary and a permanent effect. The effect is a reduction in bonds' liquidity premium caused by taking supply out of the hands of private agents desperate to sell.

\section{Conclusion}

We ask whether or not the European Central Bank's purchases of sovereign debt have affected bond markets. Following previous literature we consider the possibility of both stock and flow effects. Uniquely we provide a structural model to show how these arise. Our model suggests other factors driving bond market liquidity that one should control for when looking for these stock and flow effects. Our estimates are consistent with the model's theoretical predictions and show significant flow and stock effects. The channel through which official purchases have this permanent effect is by reducing the outstanding amount of bonds in the private market, which in turn reduces the steady-state mass of agents looking to sell the 
bond but unable to due to search frictions.

Our results join a growing literature that documents the existence of official purchases' stock and flow effects. D'Amico and King (forthcoming) and D'Amico, English, Lopez-Salido and Nelson (2012) find that Federal Reserve purchases affect the real term premium which those authors reconcile with models of preferred habitat. We also find a real effect via bond liquidity, but interpret it by a search-based economic mechanism.

Our theory suggests that the stock effect is marginally diminishing, which was not captured by our linear empirical specification. Therefore while our results suggest that past ECB purchases have had a permanent effect on bond market liquidity, care should be taken in extrapolating these effects forward to future potential purchases. Nevertheless, it is interesting to note that a program reportedly aimed at fixing market dysfunction has had effects that appear to persist after that dysfunction subsides. 


\section{References}

Ammer, J., and F. CAi (2011): "Sovereign CDS and Bond Pricing Dynamics in Emerging Markets: Does the Cheapest-To-Deliver Option Matter?," Journal of International Financial Markets, Institutions and Money, 21(3), 369-387.

Andritzky, J. R. (2004): "Implied Default Probabilities and Default Recovery Ratios: An Analysis of Argentine Eurobonds 2000-2002," University of St. Gallen, Working Paper.

Arce, Ó., S. Mayordomo, and J. I. Peña (2012): "Credit-Risk Valuation in the Sovereign CDS and Bonds Markets: Evidence from the Euro Area Crisis," Comisión Nacional del Mercado de Valores, Working Paper.

BIS (2005): "Zero-Coupon Yield Curves: Technical Documentation," Bank for International Settlements, Basel.

Chen, K., M. J. Fleming, J. P. Jackson, A. Li, and A. Sarkar (2011): "An Analysis of CDS Transactions: Implications for Public Reporting," Federal Reserve Bank of New York, Staff Report No. 51\%.

Coudert, V., And M. Gex (2010): "Credit Default Swap and Bond Markets: Which Leads the Other?," Banque de France, Financial Stability Review, 14, pp. 161-167.

D'Amico, S., And T. B. King (forthcoming): "Flow and stock effects of large-scale Treasury purchases," Journal of Financial Economics.

Delatte, A.-L., M. Gex, and A. López-Villavicencio (2010): "Has the CDS Market Amplified the European Sovereign Crisis? A Non-Linear Approach," Rouen Business School, Working Paper.

Diamond, P. A. (1982): "Aggregate Demand Management in Search Equilibrium," Journal of Political Economy, 90(5), 881-94.

Diebold, F. X., And C. Li (2006): "Forecasting the Term Structure of Government Bond Yields," Journal of Econometrics, 130, 337-364.

Duffie, D. (1998): "Defaultable Term Structure Models with Fractional Recovery of Par," Graduate School of Business, Stanford University, Working Paper.

(1999): "Credit Swap Valuation," Financial Analysts Journal, 55(1), 73-87.

Duffie, D., N. Garleanu, and L. H. Pedersen (2005): "Over-the-Counter Markets," Econometrica, 73(6), 1815-1847.

(2007): "Valuation in Over-the-Counter Markets," Review of Financial Studies, 20(6), 1865-1900.

Duffie, D., And K. J. Singleton (1999): "Modeling Term Structures of Defaultable Bonds," Review of Financial Studies, 12(4), 687-720. 
Duffie, D., And Y. Sun (2007): "Existence of Independent Random Matching," The Annals of Applied Probability, 17(1), 386-419.

Foley-Fisher, N. (2010): "Explaining Sovereign Bond-CDS Arbitrage Violations During the Financial Crisis 2008-2009," London School of Economics Working Paper.

Fontana, A., And M. Scheicher (2010): "An Analysis of Euro Area Sovereign CDS and their Relation with Government Bonds," ECB Working Paper Series, No. 1271.

Gürkaynak, R. S., B. Sack, and J. H. Wright (2007): "The U.S. Treasury Yield Curve: 1961 to the Present," Journal of Monetary Economics, 54, 2291-2304.

He, Z., and K. Milbradt (2012): "Endogenous Liquidity and Defaultable Bonds," Discussion paper.

Jarrow, R. A., And S. M. Turnbull (1996): "Pricing Derivatives on Financial Securities Subject to Credit Risk," Journal of Finance, 50(1), 53-85.

Lagos, R., and G. Rocheteau (2009): "Liquidity in Asset Markets With Search Frictions," Econometrica, 77(2), 403-426.

Nelson, C. R., And A. F. Siegel (1987): "Parsimonious Modeling Of Yield Curves," Journal of Business, 60, 473-489.

Palladini, G., and R. Portes (2011): "Sovereign CDS and Bond Pricing Dynamics in the Euro-Area," CEPR Discussion Paper, No. 8651.

Pan, J., And K. J. Singleton (2008): "Default and Recovery Implicit in the Term Structure of Sovereign CDS Spreads," Journal of Finance, 63(5), 2345-2384.

Svensson, L. E. O. (1994): "Estimating and Interpreting Forward Interest Rates: Sweden 1992-1994," NBER Working Paper Series, 4871.

(1995): "Estimating Forward Interest Rates with the Extended Nelson and Siegel Method," Sveriges Riksbank Quarterly Review, 3, 13-26. 


\section{A Appendix}

\section{A.1 Analytical Results}

Proof of Proposition 1: First note that the steady state mass evolutions are unaffected by the introduction of $\lambda_{D}$ into the model. Therefore DGP's (2005) first proposition applies directly.

Let $\tau_{l}$ denote the arrival (stopping time) of an intrinsic type shift, $\tau_{i}$ denote the arrival of a meeting with another agent and $\tau_{D}$ the arrival of the asset's default. Then the agents' value functions at time $t$ are given by

$$
\begin{aligned}
& V_{l o}=E_{t}\left[\int_{t}^{\tau_{l} \wedge \tau_{i} \wedge \tau_{D}} e^{-r(u-t)}(1-\delta) d u+e^{-r\left(\tau_{l}-t\right)} V_{h o} \mathbf{1}_{\left\{\tau_{l}=\tau_{l} \wedge \tau_{i} \wedge \tau_{D}\right\}}\right. \\
&\left.+e^{-r\left(\tau_{i}-t\right)}\left(V_{l n}+P\right) \mathbf{1}_{\left\{\tau_{i}=\tau_{l} \wedge \tau_{i} \wedge \tau_{D}\right\}}+e^{-r\left(\tau_{D}-t\right)} R(t) \mathbf{1}_{\left\{\tau_{l} \wedge \tau_{i} \wedge \tau_{D}\right\}}\right] \\
& V_{l n}=E_{t}\left[e^{-r\left(\tau_{l}-t\right)} V_{h n} \mathbf{1}_{\left\{\tau_{l}=\tau_{l} \wedge \tau_{D}\right\}}\right] \\
& V_{h o}=E_{t}\left[\int_{t}^{\tau_{l} \wedge \tau_{D}} e^{-r(u-t)} d u+e^{-r\left(\tau_{l}-t\right)} V_{l o} \mathbf{1}_{\left\{\tau_{l}=\tau_{l} \wedge \tau_{D}\right\}}+e^{-r\left(\tau_{D}-t\right)} R(t) \mathbf{1}_{\left\{\tau_{D}=\tau_{l} \wedge \tau_{D}\right\}}\right] \\
& V_{h n}=E_{t}\left[e^{-r\left(\tau_{l}-t\right)} V_{l n} \mathbf{1}_{\left\{\tau_{l}=\tau_{l} \wedge \tau_{i} \wedge \tau_{D}\right\}}+e^{-r\left(\tau_{i}-t\right)}\left(V_{h o}-P\right) \mathbf{1}_{\left\{\tau_{i}=\tau_{l} \wedge \tau_{i} \wedge \tau_{D}\right\}}\right]
\end{aligned}
$$

where dependence on $t$ has been subsumed. Using Leibniz's Rule the first-order conditions (4) follow.

Note that (4) is linear in the value functions and price, hence we have

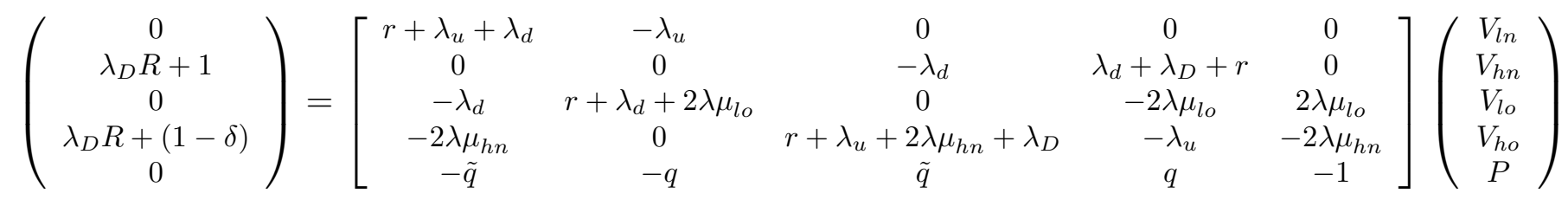

where $\tilde{q} \equiv 1-q$. The solution yields $(7)$.

QED

Proof of Proposition 2: Clearly the derivative of $P_{f}$ with respect to $s, \lambda$, and $\delta$ is zero. Now see that $\partial P_{f} / \partial \lambda_{D}=(R r-1)\left(\lambda_{D}+r\right)^{-2}$. By Assumption $1 R=\zeta / r<1 / r$ and so $R r-1$ is negative while $\lambda_{D}+r$ is positive, hence the derivative is negative.

Turning to $L$, first note that the asset is divided between low-type and high-type owners so that we have the identity $\mu_{h o}=s-\mu_{l o}$. Second, we have the identity $1-\mu_{l n}-\mu_{h o}-\mu_{l o}=\mu_{h n}$. Third, in steady state the number of low-type agents is given by $\lambda_{d}\left(\lambda_{d}+\lambda_{u}\right)^{-1}$. Combining these three statements with the steady state condition $2 \lambda \mu_{h n} \mu_{l o}+\lambda_{u} \mu_{l o}=\lambda_{d} \mu_{h o}$ we have the quadratic equation determining $\mu_{l o}$ given by $2 \lambda \mu_{l o}^{2}+\left(2 \lambda v+\lambda_{d}+\lambda_{u}\right) \mu_{l o}-\lambda_{d} s=0$ for $v=y-s$ and $y=\lambda_{u}\left(\lambda_{d}+\lambda_{u}\right)^{-1}$ as in DGP. Equivalently we can instead solve for $\mu_{h n}=v+\mu_{l o}$ from

$$
2 \lambda \mu_{h n}^{2}+\left(\lambda_{d}+\lambda_{u}-2 \lambda_{v}\right) \mu_{h n}-\left(\lambda_{d}+\lambda_{u}\right) v-\lambda_{d} s=0
$$


which will turn out to be convenient because $\lim _{\lambda \rightarrow \infty} \mu_{h n}=v \neq 0$ (by Assumption 1) whereas $\lim _{\lambda \rightarrow \infty} \mu_{l o}=0$. We will be using the derivatives of (A2) with respect to both $s$ and $\lambda$ :

$$
\begin{aligned}
\frac{\partial \mu_{l o}}{\partial s} & =\frac{\lambda_{d}+2 \lambda \mu_{l o}}{4 \lambda \mu_{l o}+2 \lambda v+\lambda_{d}+\lambda_{u}} \\
\frac{\partial \mu_{h n}}{\partial s} & =\frac{\partial \mu_{l o}}{\partial s}-1=\frac{-\lambda_{u}-2 \lambda \mu_{h n}}{4 \lambda \mu_{h n}-2 \lambda v+\lambda_{d}+\lambda_{u}} \\
\frac{\partial \mu_{h n}}{\partial \lambda} & =-\frac{2 \mu_{h n}\left(\mu_{h n}-v\right)}{4 \lambda \mu_{h n}-2 \lambda v+\lambda_{d}+\lambda_{u}} \equiv-\gamma .
\end{aligned}
$$

Below we show that $\gamma>0 \forall \lambda$. Moreover let us introduce the notation

$$
L \equiv \frac{\delta}{\Gamma_{0}} \frac{\Gamma_{1}}{\Gamma_{2}}, \quad \Gamma_{10} \equiv \frac{\Gamma_{1}}{\Gamma_{0}}, \quad \Gamma_{12} \equiv \frac{\Gamma_{1}}{\Gamma_{2}}
$$

We find that

$$
\frac{\partial L}{\partial s}=\frac{\delta}{\Gamma_{0}}\left(\frac{\partial \Gamma_{1}}{\partial s} \Gamma_{2}^{-1}-\Gamma_{12} \frac{\partial \Gamma_{2}}{\partial s}\right) .
$$

Now see that $\partial \Gamma_{1} / \partial s=2 \lambda \tilde{q}\left(\partial \mu_{l o} / \partial s\right)$ and $\partial \Gamma_{2} / \partial s=2 \lambda \tilde{q}\left(\partial \mu_{l o} / \partial s\right)+2 \lambda q\left(\partial \mu_{h n} / \partial s\right)$. Plugging these into $\partial L / \partial s$ and rearranging yields

$$
\frac{2 \delta \lambda}{\Gamma_{0} \Gamma_{2}\left(4 \lambda \mu_{l o}+2 \lambda v+\lambda_{d}+\lambda_{u}\right)}\left[\left(1-\Gamma_{12}\right) \tilde{q} \lambda_{d}+\Gamma_{12} q\left(\lambda_{u}+2 \lambda v\right)+2 \lambda \mu_{l o}\left(\tilde{q}\left(1-\Gamma_{12}\right)+\Gamma_{12} q\right)\right] .
$$

To sign this expression, note that

$$
\Gamma_{12}=\frac{2 \lambda \tilde{q}\left(\mu_{h n}-v\right)+r \tilde{q}+\lambda_{d}+\lambda_{D} \tilde{q}}{2 \lambda \tilde{q}\left(\mu_{h n}-v\right)+2 \lambda \tilde{q}(v-\tilde{q} v)+r+\lambda_{d}+\lambda_{D}+\lambda_{u}} .
$$

Because $\mu_{h n}=v+\mu_{l o}$ and $\mu_{l o} \geq 0$ then $\mu_{h n}-v \geq 0$. As a sidenote, this shows that $\gamma \geq 0$. Because $q \in[0,1]$ then $\tilde{q} \in[0,1]$ and therefore $v-\tilde{q} v \geq 0$. Hence $\Gamma_{12}>0$. To get a contradiction, assume that $\Gamma_{12} \geq 1$. But then

$$
0 \geq 2 \lambda \tilde{q}(v-\tilde{q} v)+q r+q \lambda_{D}+\lambda_{u} \quad \Rightarrow \Leftarrow .
$$

Hence $\Gamma_{12} \in(0,1)$. Therefore $1-\Gamma_{12}$ is positive and the expression for $\partial L / \partial s$ is positive.

The behavior of $L$ for large $\lambda$ can be directly inferred from DGP's (2007) first proposition and noting that $P_{f}$ is unchanged by $\lambda$.

Now see that

$$
\frac{\partial L}{\partial \lambda_{D}}=\frac{\delta}{\Gamma_{0} \Gamma_{2}}\left[-\frac{\partial \Gamma_{0}}{\partial \lambda_{D}} \Gamma_{10}+\frac{\partial \Gamma_{1}}{\partial \lambda_{D}}-\frac{\partial \Gamma_{2}}{\partial \lambda_{D}} \Gamma_{10} \Gamma_{2}^{-1}\right]
$$

and

$$
\frac{\partial \Gamma_{0}}{\partial \lambda_{D}}=R, \quad \frac{\partial \Gamma_{1}}{\partial \lambda_{D}}=\tilde{q}+2 \lambda \tilde{q} \frac{\partial \mu_{l o}}{\partial \lambda_{D}}+2 \mu_{l o} \tilde{q} \frac{\partial \lambda}{\partial \lambda_{D}},
$$




$$
\frac{\partial \Gamma_{2}}{\partial \lambda_{D}}=1+2 \lambda \tilde{q} \frac{\partial \mu_{l o}}{\partial \lambda_{D}}+2 \mu_{l o} \tilde{q} \frac{\partial \lambda}{\partial \lambda_{D}}+2 \lambda q \frac{\partial \mu_{h n}}{\partial \lambda_{D}}+2 \mu_{h n} q \frac{\partial \lambda}{\partial \lambda_{D}} .
$$

Before proceeding, note that (A2) implies

$$
\begin{aligned}
\mu_{h n}= & \frac{-\left(\lambda_{d}+\lambda_{u}-2 \lambda v\right)+\sqrt{\left(\lambda_{d}+\lambda_{u}-2 \lambda v\right)^{2}+4(2 \lambda)\left(\left[\lambda_{d}+\lambda_{u}\right] v+\lambda_{d} s\right)}}{2(2 \lambda)} \\
= & \frac{\lambda^{-1}\left(-\lambda_{d}-\lambda_{u}\right)+2 v+\sqrt{4 v^{2}+R_{1}\left(\lambda^{-1}\right)+R_{2}\left(\lambda^{-2}\right)}}{4} \\
& \underset{\lambda \rightarrow \infty}{\longrightarrow} \frac{4 v}{4}=v .
\end{aligned}
$$

where the second line follows by multiplying by $1=\lambda^{-1} / \lambda^{-1}$ where $R_{1}$ is $O\left(\lambda^{-1}\right)$ and $R_{2}$ is $O\left(\lambda^{-2}\right)$, therefore limits are finite and the result follows. Therefore we can write

$\frac{\partial L}{\partial \lambda_{D}}=\frac{\delta}{\Gamma_{0} \Gamma_{2}}\left[\tilde{q}-\Gamma_{10} R-\Gamma_{12}+2\left(\mu_{h n}-v\right) \tilde{q} \eta\left(1-\Gamma_{12}\right)-2 \lambda \eta \tilde{q} \gamma\left(1-\Gamma_{12}\right)-2 \Gamma_{12} q \eta\left(\mu_{h n}-\lambda \gamma\right)\right]$

which is difficult to sign in general when $\eta$ is nonzero since the fifth and sixth terms are of the opposite sign as the fourth term whatever is $\eta$. In the main part of Proposition 2 we have $\eta=0$ and therefore the sign is dictated by $\tilde{q}-\Gamma_{10} R-\Gamma_{12}$. We know that $\Gamma_{12}$ is positive. However, note

$$
\Gamma_{10} R=\frac{\tilde{q} \lambda_{D}+r \tilde{q}+\lambda_{d}+2 \lambda \mu_{l o} \tilde{q}}{\lambda_{D}+1 / R}=\tilde{q} \frac{\lambda_{D}+r+\lambda_{d} / \tilde{q}+2 \lambda \mu_{l o}}{\lambda_{D}+1 / R}
$$

and this is not generally-speaking above or below $\tilde{q}$. Hence our inability to sign $\partial L / \partial \lambda_{D}$ absent further parametric restrictions. However, it is possible to look directly at $L$ and note that it is of the form $O(\lambda) / O\left(\lambda^{2}\right)=O\left(\lambda^{-1}\right)$ and therefore $L \underset{\lambda \rightarrow \infty}{\longrightarrow} 0$.

When $\lambda\left(\lambda_{D}\right)$ is bounded, then $L$ is still of the form $O(\lambda) / O\left(\lambda^{2}\right)=O\left(\lambda^{-1}\right)$ which is we needed above in our calculation of $\lambda_{D}$ 's effects on $L$ and $P_{f}$. Therefore those results hold even when $\lambda$ is a bounded function of $\lambda_{D}$.

To see the sufficiency of the provided condition $\frac{\lambda_{d}}{1-q}+\lambda \mu_{l o}>\left(\frac{1}{\zeta}-1\right) r$, consider the derivative $\partial L / \partial \lambda_{D}$ in (A6) and the expression (A7). $\Gamma_{10} R$ is greater than $\tilde{q}$ when $\left(\lambda_{D}+r+\right.$ $\left.\lambda_{d} \tilde{q}+2 \lambda \mu_{l o}\right)\left(\lambda_{D}+1 / R\right)^{-1}$ is greater than unity. This implies

$$
\begin{aligned}
r+\frac{\lambda_{d}}{\tilde{q}}+2 \lambda \mu_{l_{o}} & >1 / R \\
& \frac{\lambda_{d}}{\tilde{q}}+2 \lambda \mu_{l_{o}}>\left(\frac{1}{\zeta}-1\right) r
\end{aligned}
$$

Therefore when (A8) holds and $\eta=0$, (A6) has a sign dictated by

$$
-\tilde{q}\left(\Gamma_{10} R-1\right)-\Gamma_{12},
$$

that $\Gamma_{10} R-1$ and $\Gamma_{12}$ are positive, and therefore $\partial L / \partial \lambda_{D}<0$.

The results for the price $P$ follow directly from the above results for $P_{f}$ and $L$. 
The $\frac{\lambda_{d}}{1-q}+\lambda \mu_{l o}>\left(\frac{1}{\zeta}-1\right) r$ condition For our data, risk-free rates have been quite low and inflation tame. Hence $r$ will be no more than an annual rate of 0.05. Rules of thumb for bonds' recovery value hover around $40 \%$ of par, which implies $\zeta$ is around 0.4 . These values would imply the right hand side of the condition is 0.125 .

The term $\lambda \mu_{l o}(\lambda)$ is $O\left(\lambda^{1 / 2}\right)$ by the following argument. DGP's (2005) proof of their first proposition (characterizing $\mu_{l o}$ as the positive root of a quadratic equation) along with the identity $\mu_{h n}=v+\mu_{l o}$ gives us

$$
\begin{aligned}
\mu_{h n} & =\frac{-\left(\lambda_{d}+\lambda_{u}-2 \lambda v\right)+\sqrt{\left(\lambda_{d}+\lambda_{u}+2 \lambda v\right)^{2}+8 \lambda \lambda_{d} s}}{4 \lambda} \\
& =\frac{-\lambda_{d}-\lambda_{u}}{4 \lambda}+\frac{v}{2}+\frac{\lambda_{d}+\lambda_{u}}{4 \lambda}+\frac{v}{2}+\frac{R_{1}(\sqrt{\lambda})}{4 \lambda}
\end{aligned}
$$

where $R_{1}(\sqrt{\lambda})$ is $O(\sqrt{\lambda})$. Combining with the terms we have

$$
\mu_{h n}=v+R_{2}\left(\lambda^{-1 / 2}\right)
$$

where, considering $R_{1}$, we can see that $\sqrt{\lambda} R_{2}\left(\lambda^{-1 / 2}\right) \neq 0$. Therefore $\mu_{h n}=v+O\left(\lambda^{-1 / 2}\right)$ and then $\mu_{l o}=O\left(\lambda^{-1 / 2}\right)$. Thus $\lambda \mu_{l o}$ is $O\left(\lambda^{1 / 2}\right)$ and nonzero. Hence the condition is satisfied for even extremely low values of $\lambda$ like 1 where the expected time between matches is about $250 /(2 \times 1)=125$ days. In every simulation shown in the paper (in all figures) we find $\lambda \mu_{l o}$ to be greater than unity.

Alternatively, if one is uncomfortable pinning down the matching intensity, we can instead satisfy the condition by choosing $\lambda_{d}$ and $q$ appropriately: These appear because $\lambda_{d}$ helps control the steady state mass of low-type investors while the latter contains $q$ the bargaining power of the low-types who are sellers of the asset.

\section{A.2 Measuring Liquidity}

In this section, we describe our estimation of the different portions of the bond yields that will both motivate the construction of our model and eventually allow us to estimate the effects of ECB purchases on bond liquidity. The technical description of our estimates is deferred to below. The top two panels of Figure A1 shows the breakdown of the Italian and Spanish yields into the German rate, which we take to be the risk free rate, and a combined term which encompasses both the default risk on the bonds and our object of interest, the bond liquidity premium.

Our eventual estimate of the liquidity premium depends crucially on the scale of the default probability. Since the default risk premium depends both on the probability of default and the recovery rate conditional upon default, we can only identify the default rate up to a scaling constant. The bottom two panels show the default probability we would estimate under different assumptions on the recovery rate. High recovery rates are associated with high default probabilities and vice versa.

We use CDS price data to construct an empirical estimate of the default probability that is distinct from bond liquidity. Eventually, this will allow us to pin down the response of 


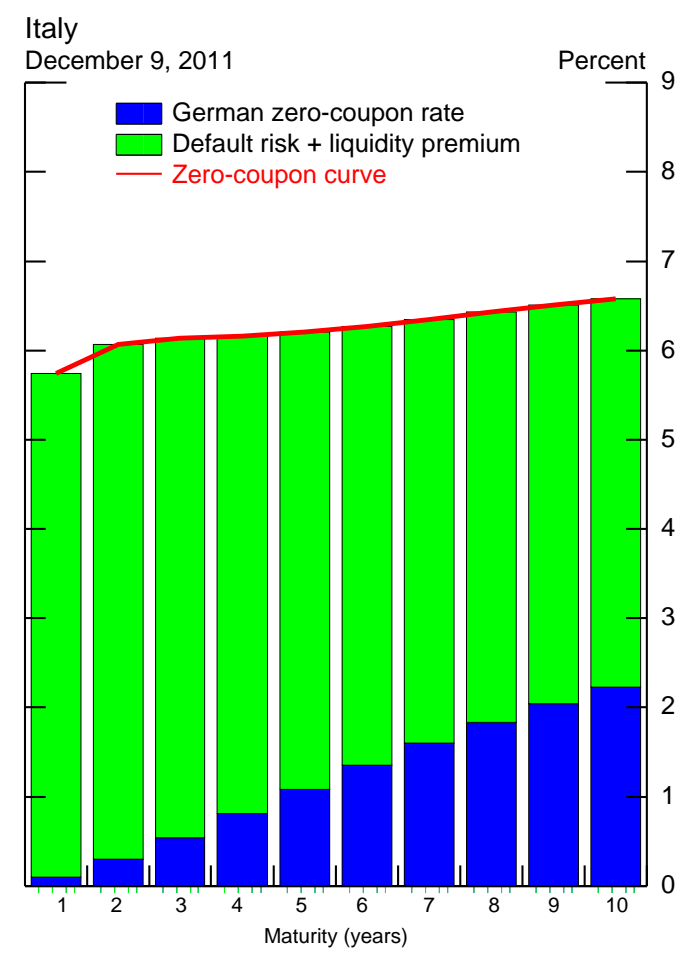

Spain

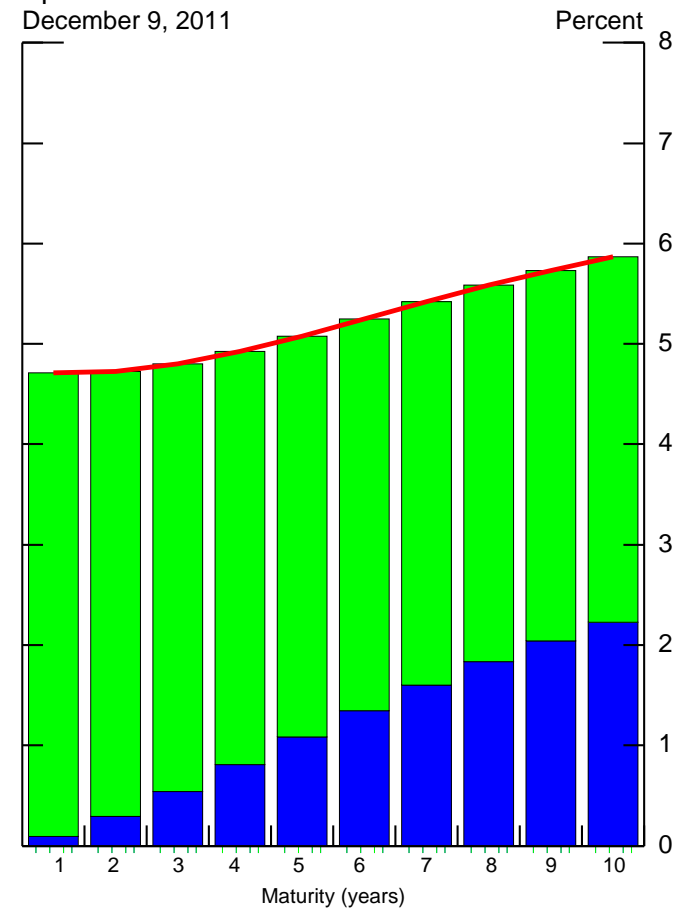

Italy

Spain
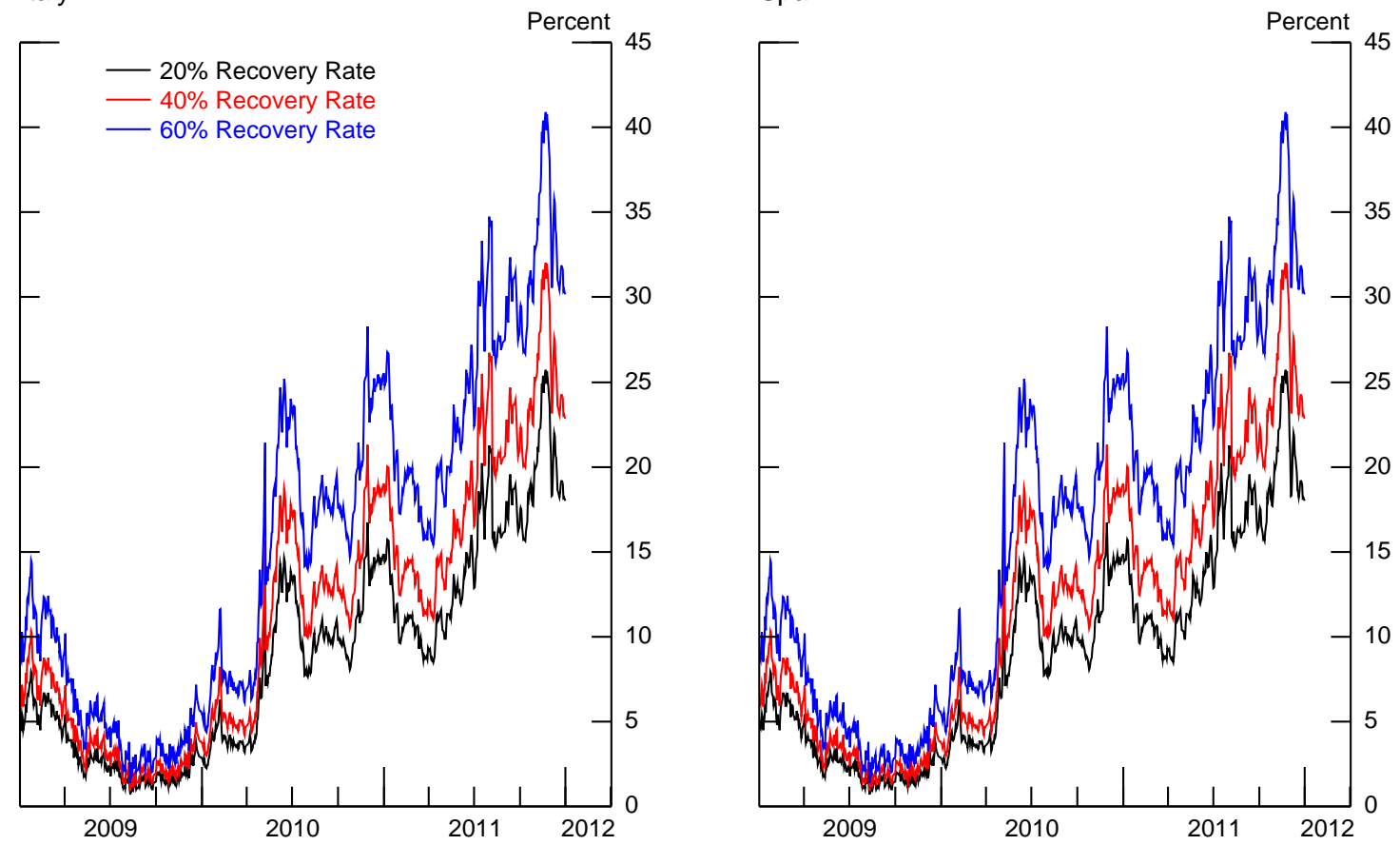

Figure A1: Italian and Spanish Yield Curve Decomposition and Default ProbABILITIES UNDER VARIOUs RECOVERY RATES

bond liquidity to ECB purchases. The CDS-implied default probabilities computed at the five-year horizon are plotted in Figure A2. These figures reveal that market-implied default 


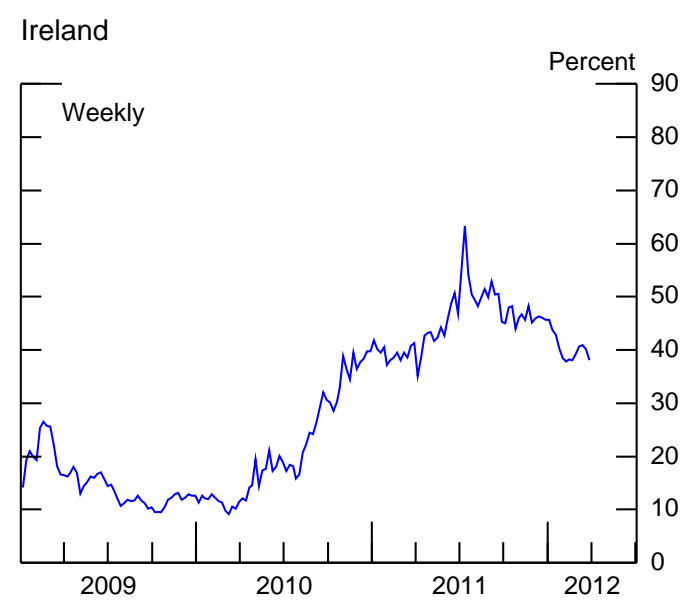

Portugal
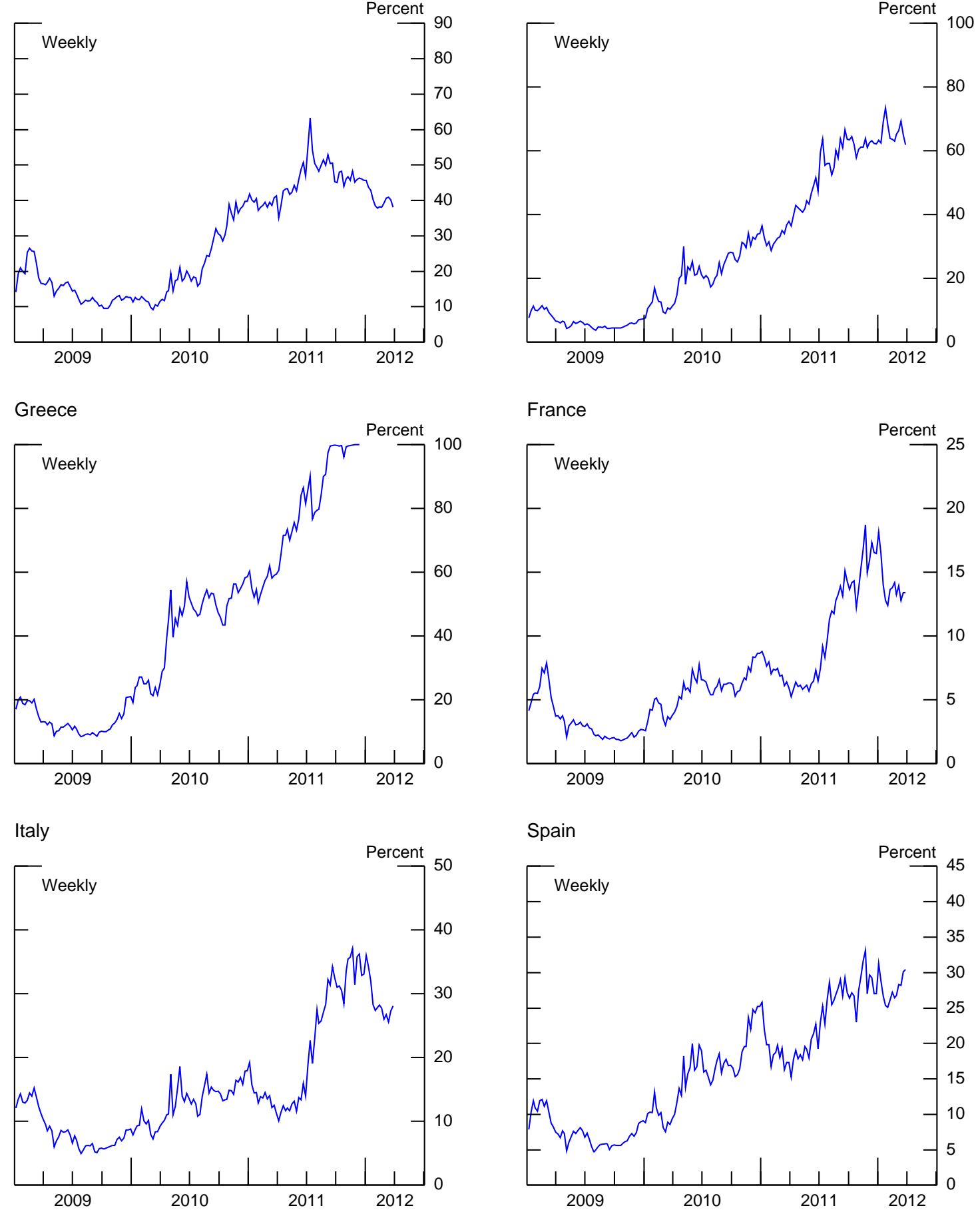

Figure A2: CDS-Implied Default Probabilities

probabilities have varied tremendously across countries and over time. Default probabilities have mostly risen across the countries we consider, but with different timing and to different degrees. The probability of Irish default peak in mid-2011 and has since come down a bit. Meanwhile Portuguese default is increasingly imminent, and of course Greek default actually 
occurred. The probability of French default was reasonably low until mid-2011 when it shot from 5\% to 15\% on the back of concerns over French banks' exposure to peripheral Europe. The Italian default probability had been slowly rising, but then jumped up alongside France's, while the Spanish default probability has more or less trended upwards since mid-2009. This evidence makes clear that variation in default probability is a notable feature of the sovereign bonds which are the key focus of our study.

We identify the bond liquidity premium by subtracting the implied probability of default from the CDS market from the bond default risk and liquidity premium. Notice, that we are implicitly measuring a difference in relative liquidity in these two marketsthe true default probability cancels and we have a liquidity term for CDS and a liquidity term for bonds. In our empirical estimation, we will make a distributional assumption on CDS liquidity (we assume that is is i.i.d.) that will enable us to measure changes in bond liquidity.

Figure A3 shows the evolution of relative liquidity in the six countries included in our study from 2009 through 2012. If we assume that CDS liquidity is i.i.d., then any systematic deviation in the series indicates changes in bond market liquidity. Specifically, a decrease in the series indicates an impaired bond market. There have been great differences in bonds liquidity across countries and over time. As further explained in Section 2, we interpret upward movements in these variables as indicating that bond market liquidity conditions are improving relative to CDS liquidity conditions. We focus discussion on the difference in default probabilities although clearly the CDS basis also shown in the figure echoes this narrative.

We include the CDS basis because previous studies have focused on these spreads rather than the differences in the implied probability of default. There is no substantive difference between the two series, but we find the difference in probabilities to be more intuitive and to better fit with our model. In the empirical section, we will run all of our results for both series.

We can map the effect of the SMP purchases into changes in bond market liquidity using the charts in figure 5. At the beginning of our sample both Irish and Greek bond (relative) liquidity conditions were quite variable, while conditions in Portuguese bond and CDS markets were stable. Going into 2010 Portuguese bond liquidity conditions started to fluctuate much more as problems with the nation's fiscal situation started to gain attention. Downward spikes appear near the end of April 2010, indicating that bond liquidity worsened leading into the ECB's introduction of its Securities Market Programme in May. Bond liquidity improves in all markets, but the marked improvement falls off soon thereafter. Through the end of 2010 we see trending improvement that is interrupted by downward spikes leading to renewed SMP purchases in November and December 2010.

Figure A4 runs through the special case study of Spain and Italy. The top panel of the figure shows five-year bond spread for the two countries. For reference throughout, we keep the vertical lines first used in Figure 1; they mark the same events. Because the spreads already control for the German rate, the implied probability of default (which of course also include the bond liquidity premium) shown in panel 2 mirror the movements in the spreads. The third panel shows the difference between bond and CDS default probabilities. This measures of bond liquidity (relative to CDS liquidity) forms the basis for our empirical 

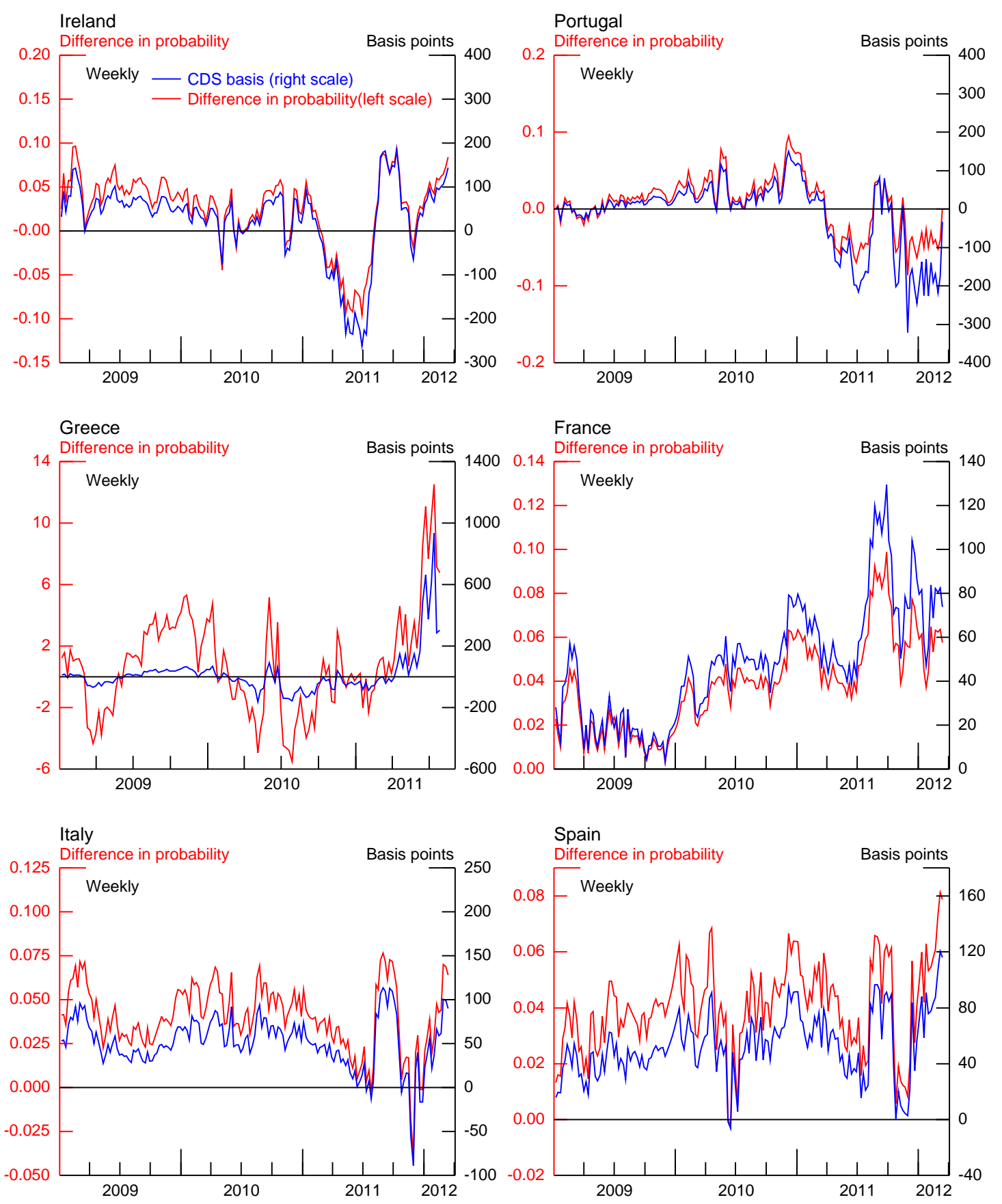

Figure A3: Bond Liquidity Measures

investigation of the effects of SMP purchases.

The bottom panel of Figure 6 shows an alternative direct measure bond liquidity: the bidask spread for bonds. Reassuringly, since we use Germany as our base case, German spreads stay low and stable throughout the study, indicating no interesting variation in liquidity over the period. Spanish and Italian spreads move inversely to the data shown in the previous panel. Note in particular that the highest level of bond market stress was evident in late 
Five-year Bond Yields

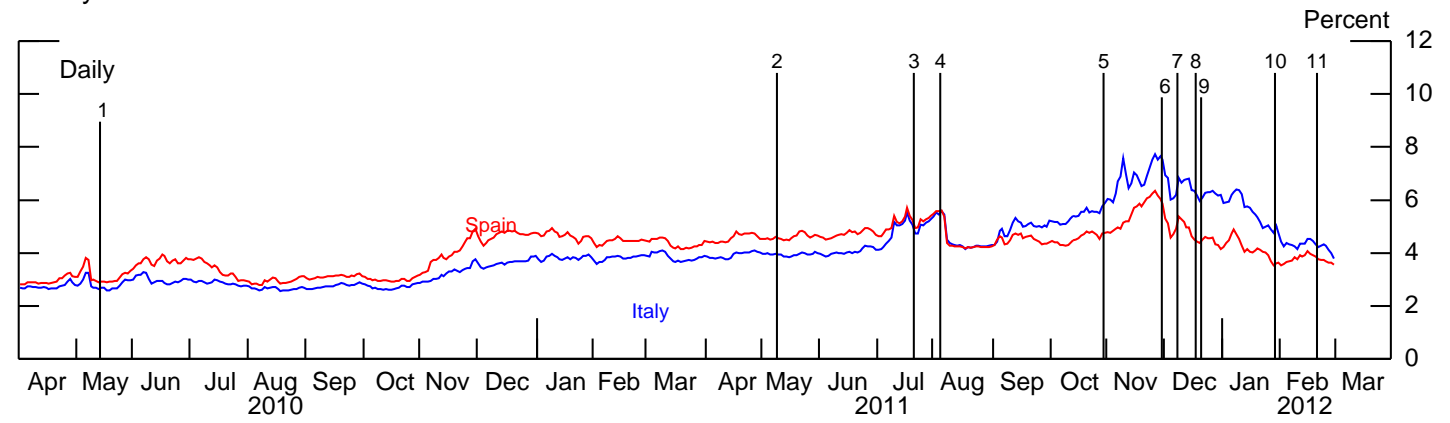

Five-year Implied Probability of Default from Bonds

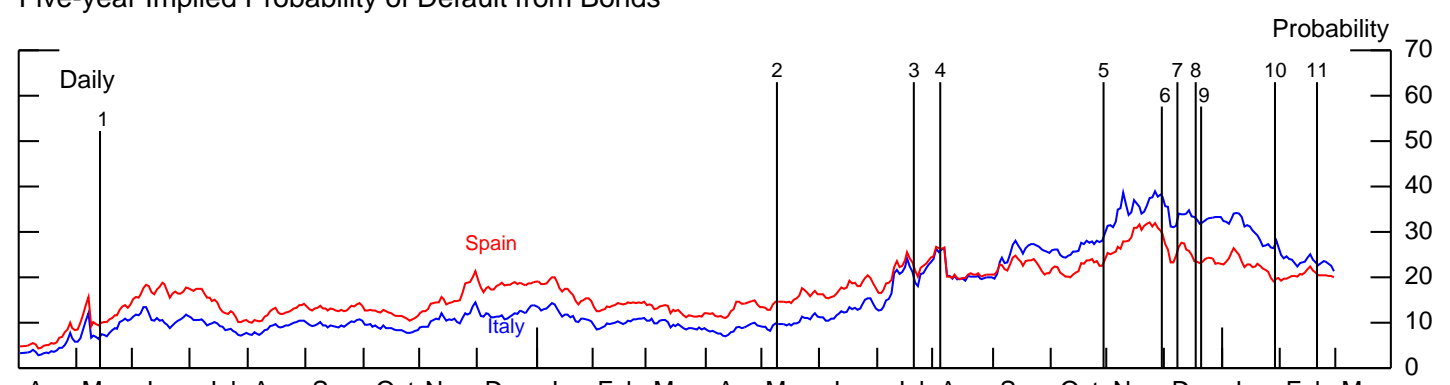
Apr May Jun Jul Aug Sep Oct Nov Dec Jan Feb Mar Apr May Jun Jul Aug Sep Oct Nov Dec Jan Feb Mar 2012

Five-year Spread Between CDS and Bond Probabilities of Default

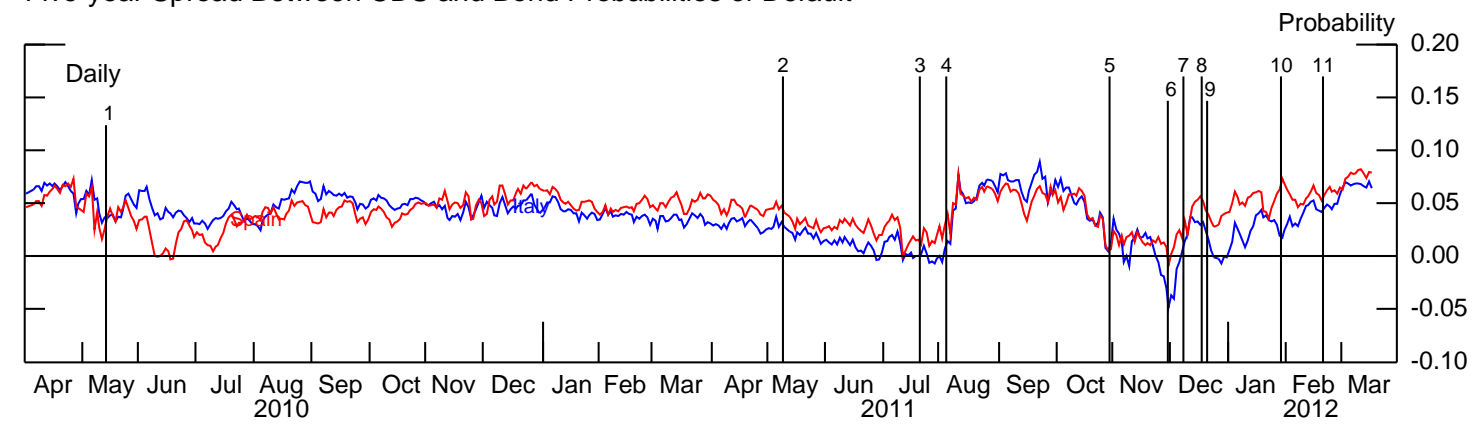

Bid-Ask Spreads for 10-Year Generic Sovereign Bonds

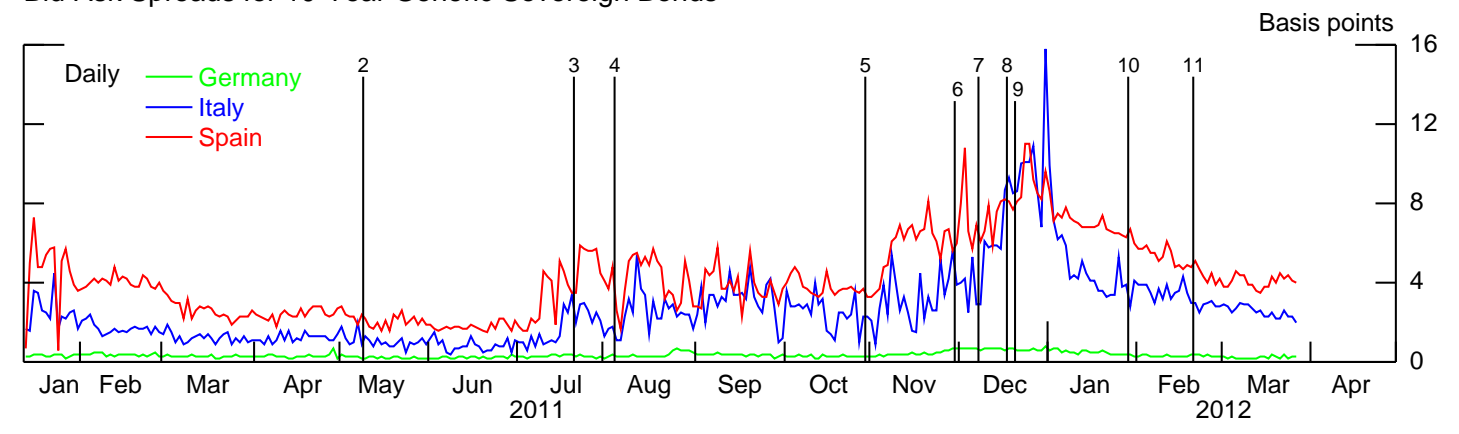

Figure A4: Case Study: Spain and Italy

November 2011, the same period where bid-ask spreads moved considerably wider. 


\section{A.3 Present Value Approach}

Suppose that the time- $t$ price of a generic defaultable asset $j$ which matures $H$ periods from now is given by the following present value relationship:

$$
\begin{aligned}
\text { Price }_{j, t}= & \int_{t}^{t+H} \text { DiscountRate }_{j, s} \times \\
& \quad\left(\text { CashFlow }_{j, s} \times\left(1-\text { ProbabilityOfDefault }_{j, s}\right)\right. \\
& \left.\quad+\text { RecoveryValue }_{j, s} \times \text { ProbabilityOfDefault }_{j, s}\right) d s
\end{aligned}
$$

This expression is familiar: asset-owners equate today's price of their assets to discounted expected future cash flows. For any instrument that has a non-zero probability of defaulting, agents acknowledge that a future period can bring either cash flow (when the asset is not in default) or some recovery value (when the asset defaults). These outcomes are weighted according to the probability that the agent assigns to the default event, and then summed.

The DiscountRate $_{j, s}$ term with which the agent discounts the two potential cash flows at any future point in time is composed of two pieces that we highlight. The first piece consists of the agent's expected future consumption stream and her preferences. The other represents the agent's expectations regarding the future liquidity costs associated with the asset. While we defer being explicit on what exactly this liquidity cost is until Section 2, it suffices to say at this point that the agent prices the risk that an asset is not immediately transferable for an amount of the consumption good equal to its price. Similar to Duffie and Singleton (1999) we assume that this liquidity part of the discount rate is additively separable:

$$
\text { DiscountRate }_{j, s}=\text { MarginalUtility }_{s}+\text { LiquidityCost }_{j, s} .
$$

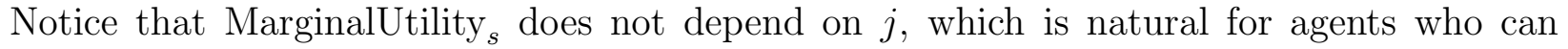
easily adjust their portfolio between assets.

Now suppose there is a asset $j_{r f}$ for which liquidity cost and probability of default are both negligible. Imagine this "risk-free" asset being traded over-the-counter but (thinking ahead to our model in Section 2) there are so many available counterparties that its market is almost like an Walrasian exchange. For this asset the price is equal to

$$
\text { Price }_{j_{r f}, t}=\int_{t}^{t+H} \text { MarginalUtility }_{s} \times \text { CashFlow }_{j_{r f}, s} d s
$$

Furthermore, if all of its future cash flows are known at time $t$ then this asset reveals the cumulative sum of future expected marginal utilities. Therefore, if we were to have a $j_{r f^{-}}$ asset for each possible $H$, we can calculate MarginalUtility $y_{s}$ for any future period. Once this first piece of the discount rate is made observable this way, we can translate asset $j$ 's price into a amalgam of expected probabilities of default and liquidity costs, if we know asset $j$ 's cash flows and know or assume its recovery value upon default. In other words, with assets available for different $H$ we can calculate the integrand of (A9) for discrete periods and the

only unknowns will be LiquidityCost ${ }_{j, s}$ and ProbabilityOfDefault ${ }_{j, s}$. We refer to this as the default/liquidity amalgam. 
We bring this approach to price data for bonds and CDS on European sovereigns. Bonds and CDS have known cash flows and we follow the majority of the literature in assuming a known and identical recovery value for both in order to identify probabilities of default. We take German bunds as our risk free asset for sovereign bonds while we take euro-area swap rates as our risk free asset in our CDS calculations. German bunds are arguably defaultfree and extremely liquidly traded and it is natural to think of an identical marginal bond investor being active in the various European sovereign bond markets due to Europe's shared currency and payment systems. Therefore we use German debt to back out default/liquidity amalgams from the European sovereign bonds in our sample. Separately, CDS protection on a European sovereign bond position provided by a typical dealer would arguably reduce the credit risk on such a bond position to roughly that of lending in the swap market. Because of the credit risk of the counterparty dealer selling protection, the default risk on the CDS-protected bond position would presumably not be as as low as that of sovereign bonds.

As Duffie (1999) demonstrates, an exact arbitrage pricing relation exists among a risky floating rate bond trading at par, a risk-free par floater of the same maturity, and a CDS contract of the same maturity on the risky bond. Consequently, the CDS basis, which is commonly defined a the CDS spread minus the spread between the risky and risk free rates should be equal to zero, and one might therefore suppose that the resulting default/liquidity amalgams for European bonds and CDS that we focus on in this paper are identical to one another. Indeed, the two assets theoretically reflect the same default event and the probability of default priced by bonds and CDS should therefore be identical. ${ }^{21}$ In this case the difference between bond and CDS default/liquidity amalgams come solely from differences in the two assets' LiquidityCost ${ }_{j, s}$. This is the important assumption and insight that allows us to compare bond and CDS prices (and measures constructed thereof) to measure their markets' relative liquidity conditions.

Similarly, because any non-zero CDS basis constitutes an arbitrage opportunity that should be arbitraged away by investors, one could suppose that the liquidity conditions in both markets should be the same too. ${ }^{22}$ In practice, however, the basis can be either positive or negative for a variety of reasons. Some commonly stated reasons include one market leading the other in terms of price discovery, the "cheapest-to-deliver" option that is part of standard CDS contracts, liquidity premiums in either the CDS or bond market, counterparty risk, flight-to-safety flows, or an exchange rate effect when the CDS contract is written in a different currency than the reference bonds. A substantial literature has documented and analyzed non-zero bases in the corporate bond markets. Fewer studies have analyzed the CDS basis for sovereigns. An interesting study is Ammer and Cai (2011) who analyze the basis for nine emerging market countries and provide evidence of a significant effect of the cheapest-to-deliver option, consistent with the on average positive basis spread that they

\footnotetext{
${ }^{21}$ However, recent events in Greek bond and CDS markets have strained the credibility of the assumption that bond and CDS default events are identical. Nonetheless, since at the time of this draft Greek CDS were triggered by the voluntary private sector involvement plan put in place by Greek officials, we feel comfortable maintaining this commonplace assumption.

${ }^{22}$ This despite the fact that European sovereign CDS volume is relatively small compared to the stock of outstanding European debt, even though the European CDS market has grown substantially since the onset of the financial crisis, see the data that is available on www.dtcc.com.
} 
record for each country. Ammer and Cai also find that the CDS market often leads the bond market in price discovery, but that this is less likely to be the case for countries that have larger bond issuance, indicating that relative liquidity plays a role. Our model elaborates on that observation by focusing attention on the systematic drivers of bond market liquidity and using those to explain differences between bond and CDS price measures like the CDS basis.

In our empirical analysis, we find that since the onset of the financial crisis the CDS basis for our sample of European sovereign nations has been positive on average, but with substantial swings into both positive and negative territory. This finding is not new, however, as several recent studies have examined the CDS basis for euro-area countries and have documented the same patterns, see Coudert and Gex (2010), Foley-Fisher (2010), Fontana and Scheicher (2010), and Palladini and Portes (2011). ${ }^{23}$ These papers find that the basis is on average positive, and non-zero for prolonged periods of time which, as stated by Palladini and Portes (2000) is "consistent with the hypothesis of imperfections in the arbitrage relationship". Although they record the apparent result of these imperfections, all of the above papers, with the exception of Foley-Fisher (2010), leave these imperfections unexplained and do not provide any mechanism, or model-based approach attempted at explaining the channel(s) through which imperfections have an effect on the basis. Our contribution in this paper is to try and do just that. Although very different in terms of specifics of the model, in that respect our paper is close to Foley-Fisher (2010) who constructs a heterogenous-agent model in which agents have different views on whether or not a country is going to default on its debt obligations. Foley-Fisher shows that one only needs a small divergence in opinions to generate the violations of arbitrage that led to the positive basis observed for European countries till early 2010. However, it is unclear to what extent this model can also explain the negative basis that we observed during 2011.

Similar to Foley-Fisher (2010) we offer a model-based frame-work that can shed light on the CDS basis being non-zero. Ultimately, however, we are not after an explanation for the non-zero CDS basis or, more generally, for variations in the basis over time. As noted in the Introduction, we are primarily interested in analyzing the differential liquidity costs of European CDS and bond markets. We use variations in this measure, which we identify as being the difference between default probabilities computed from CDS and bonds (either directly in probability space or translated into yield space) to analyze the causes and effects of the ECB's purchases in European sovereign bond markets. Under our assumption that CDS and bond markets should reflect the same probability of default, taking the difference in probability is in essence the same as taking the difference in liquidity premia. Our model in Section 2 represents the CDS basis as indeed the difference between liquidity premia for CDS and bonds. The mechanism by which we explain a nonzero basis is present for

\footnotetext{
${ }^{23}$ With the exception of Foley-Fisher (2010), these papers primarily use a reduced-form Vector Error Correction Model approach to test for the existence of a long-run relation between CDS spreads and bond spreads, and to analyze which market tends to leads which. The general conclusion reached is that the CDS market leads the bond market for the countries that have seen their CDS spreads rise the most during the crisis: Portugal, Ireland, Greece, Italy and Spain. While these papers use a linear and predominantly full-sample approach, Delatte, Gex and López-Villavicencio (2010) and Arce, Mayordomo and Peña (2011) show that allowing for a time-varying relationship as well as a nonlinear relationship, respectively, can help to better understand the relationship between European CDS and bond markets.
} 
assets with small default probabilities and is not required to be zero in the long run. The first aspect is important since our focus is on advanced European economies with widely differing probabilities of default. ${ }^{24}$ The second aspect of the mechanism is important since our analysis focuses on the period when the ECB was purchasing sovereign bonds in the secondary market. These data are inconsistent with the hypothesis of a zero CDS basis, even in the long-run.

Our desire to analyze relative liquidity, or the relative probability of default, is the reason why we do not rely primarily the more commonly used, and more easily obtained, CDS basis. Computing the standard CDS basis for a specific maturity, say the often-used 5year maturity, can make results and conclusions dependent on the volatility in quotes for these individual CDS and bond contracts, with a single bad quote at a particular horizon potentially having a substantial impact on results. We instead opt to use the entire term structure of CDS spreads as well as the entire spectrum of available bond prices for all available maturities to draw from. We use these to construct term structures of default probabilities from CDS and bonds, and then use these to in turn construct a term structure of relative liquidity, for each country separately. Differencing these default probabilities produces a more efficient measure of the relative liquidity conditions in bond and CDS markets. ${ }^{25}$ The methodology that we use is described next.

\section{A.4 Extracting Default Probabilities from CDS and Bond Mar- kets}

In this section we describe in detail our approach of extracting probabilities of default and our measure of relative liquidity from sovereign bond prices and sovereign CDS spreads. Unlike Duffie and Singleton (1999) and Pan and Singleton (2008), who simultaneously combine the information from the cross section dimension as well as the time-series dimension, we extract our estimates on a day-to-day basis, by separately fitting each day the cross section of sovereign bond prices and sovereign CDS prices. In both fitting procedures we follow Jarrow and Turnbull (1995) and account for the presence of a credit event arrival process by means of a Poisson counting process. A credit event is characterized as the first event of this counting process which occurs at some time $t^{*}$ with a probability defined as

$$
P\left[t^{*}<t+d t \mid t^{*} \geq t\right]=\lambda_{D, t}(d t) d t
$$

This implies that the probability of the credit event, in our case default, occuring within the time interval $[t, t+d t)$, conditional on no default having occurred till time $t$, is proportional to the hazard rate function $\lambda_{D, t}(d t)$ and the length of that time interval, $d t$. We assume that the hazard rate is a horizon-dependent function and for bond prices we assume it is a continuous function as this better fits with our approach of extracting zero-coupon curves

\footnotetext{
${ }^{24}$ That said, some of the above mentioned studies do find that the basis tends to be more often nonzero for European countries when the likelihood of a sovereign default is higher. This is in line with Ammer and Cai (2011) who find that the cheapest-to-deliver option hypothesis has the most support in default-prone emerging economies.

${ }^{25}$ Nonetheless, the appendix reports results using the CDS basis instead. Our qualitative findings remain.
} 
from bond prices, while for CDS spreads we assume it is a flat step function. ${ }^{26}$

While an easier approach would be to assume that the hazard rate is constant over any horizon, i.e. $\lambda_{D, t}(\tau) \equiv \lambda_{D, t}$, we feel this is unnecessary restrictive, and counterintuitive. One can think of obvious examples why agents would think it is more likely that a country is to default between, say, two and three years from now compared to between today and a year from now if the country has for example large bond redemption obligations due in two years time and it seems unlikely that the country will be able to meet these at that time.

\section{A.4.1 From Bond Prices}

For each day in the sample, and for each of the six countries in our country panel separately, we estimate the zero-coupon curve that is embedded in the cross section of available bond prices for that particular day. We do so by using a modified version of the popular parametric curve-fitting approach of Nelson and Siegel (1987). This method is very popular among central banks for estimating daily zero coupon rates, see BIS (2005), and often used in practice as well. Assuming that bond prices are default free, which is our assumption for the German bunds that we choose as use our risk free assets in (A11), Nelson and Siegel (1987) stipulate that the zero coupon curve is governed by the following functional form:

$$
y_{r f, t}(\tau)=\beta_{1, t}+\beta_{2, t}\left[\frac{1-\exp \left(-\frac{\tau}{c_{t}}\right)}{\left(\frac{\tau}{c_{t}}\right)}\right]+\beta_{3, t}\left[\frac{1-\exp \left(-\frac{\tau}{c_{t}}\right)}{\left(\frac{\tau}{c_{t}}\right)}-\exp \left(-\frac{\tau}{c_{t}}\right)\right]
$$

with $y_{t}(\tau)$ being the time- $t$ zero yield for maturity $\tau$. The Nelson Siegel curve depends on the parameters $\beta_{t, 1}, \beta_{t, 2}$ and $\beta_{t, 3}$ while $c_{t}$ is a constant associated with the equation. The different parts of (A13) are designed to capture the well-known level, slope and curvature which are typically present in term structure data. ${ }^{27}$

When estimating zero coupon curves for the countries in our sample, we have to account for the fact that bonds for these countries will be priced in the market taking into account the probability of sovereign nations defaulting on their debt obligations, i.e. we have to apply (A9) instead of (A11). We do so by using the recovery of face value (RFV; see Duffie, 1998) formulation which stipulates that when default occurs, a bond holder will no longer receive any coupons, but does receive a fractional recovery of the face value on his bonds upon default, with the recovery rate assumed to be equal across all bonds. We therefore use (A9) to value the bond using a binomial tree model which at any point in time weighs the two possible outcomes of default/no default and the accompanying cashflow payments by the (conditional) probability of each outcome occurring. The (discrete) probability of not experiencing

\footnotetext{
${ }^{26}$ Although the hazard rate is horizon-dependent, we do assume that it is independent of interest rates and recovery rates.

${ }^{27}$ Note that most central banks that report their zero-coupon curve estimates to the BIS, do not directly use the Nelson-Siegel specification, but instead use the Svensson $(1994,1995)$ extension which adds a second curvature factor to (A13). This additional curvature factor comes with an additional parameter $\beta_{4, t}$ and has a second constant associated with it, see Svensson (1995) for more details. The German Bundesbank uses the Svensson-Nelson-Siegel model as well, but for ease of exposition we focus solely on the original Nelson-Siegel specification here.
} 
a default from time $t$ to a future time point $t^{*}$ equals $P\left[t^{*}>t\right]=\exp \left(\sum_{\tau=t}^{t^{*}} \lambda_{D, b o n d s, t}(\tau) \Delta \tau\right)$. We discount the cashflows using German zero-coupon rates as the risk free term structure. The probability of default/no default during a given period is specified by the Poisson probability in (A12). We specify the time-varying hazard rate for bonds, $\lambda_{D, \text { bonds }}(t)$, using the same Nelson-Siegel parametric form as in (A13), but we take the exponent to ensure that it is positive everywhere on its domain; $\lambda_{D, b o n d s, t}(\tau)=\exp \left(\lambda_{D, b o n d s, t}^{*}(\tau)\right)$ with $^{28}$

$$
\lambda_{D, b o n d s, t}^{*}(\tau)=\delta_{1}+\delta_{2}\left[\frac{1-\exp \left(-\frac{\tau}{c_{\lambda, t}}\right)}{\left(\frac{\tau}{c_{\lambda, t}}\right)}\right]+\delta_{3}\left[\frac{1-\exp \left(-\frac{\tau}{c_{\lambda, t}}\right)}{\left(\frac{\tau}{c_{\lambda, t}}\right)}-\exp \left(-\frac{\tau}{c_{\lambda, t}}\right)\right]
$$

Using this approach we obtain "default and liquidity-adjusted" zero coupon curves, as in Duffie and Singleton (1999), for the countries in our sample. ${ }^{29}$ In essence it comes down to specifying each country's zero coupon rates, $y_{t}(\tau)$, as the sum of three components,

$$
y_{t}(\tau)=y_{r f, t}(\tau)+\lambda_{D, \text { bonds }}(t) \times(1-R(t))+L(t)
$$

where $R(t)$ is the recovery value on the face value of the bond and where $L(t)$ accounts for (il)liquidity in the bond market. This equation shows that in order to take the next step and extract default probabilities from bond prices, one can do so after setting the recovery rate value. Here and throughout we set the recovery rate to $40 \%$ of face value. In the next section we show, however, that our results do not crucially depend on this recovery rate assumption. With the recovery rate assumption in hand, we can then identify a term structure of default probabilities from the estimated zero coupon curves. We obtain the default probability estimates by minimizing the sum of squared bond pricing errors and optimizing over the parameters of the hazard rate function.

\section{A.4.2 From CDS spreads}

We estimate the term structure of default probabilities from CDS spreads by sequentially building this up from CDS contracts with increasingly longer maturities using a bootstrap approach. We do by equating the time- $t$ present value of the CDS premium leg to that of the protection leg. The premium leg of a CDS contract is the series of payments of the CDS spread, $\operatorname{Spr}_{C D S}(\tau)$, made until maturity $\tau$ of the contract or until default occurs. The protection leg is the payment of $(1-r)$ percent of the face value $F$ of the bond upon default.

\footnotetext{
${ }^{28}$ Estimating the constant $c_{\lambda, t}$ alongside the parameters adds additional nonlinearity to the hazard rate curve and complicates the estimation procedure. Therefore, similar as in Diebold and Li (2006) who use the Nelson-Siegel model to fit U.S. Treasury yields, we fix $c_{\lambda, t}$ to a pre-determined constant such that in this case the curvature factor in the hazard rate function reaches it maximum loading at a maturity of 18 months. Varying the constant, however, showed that our results do not crucially depend on this assumption.

${ }^{29}$ Another approach at making the hazard rate time-varying is proposed in Andritsky (2004) who specifies the hazard rate as a Gumbell distribution and uses it to extract default probabilities from Argentine Eurobonds.
} 
At time $t$ we therefore set

$$
\begin{aligned}
\text { Price }_{\text {PremiumLeg, }} & =\text { Price }_{\text {ProtectionLeg, },} \\
F \times \operatorname{Spr}_{C D S}(\tau) \times \sum_{k=t}^{\tau-1} B_{t, k} \times P\left[t^{*}>k\right] & =(1-R(t)) \times F \times \sum_{k=t}^{\tau-1} B(t, k) \times\left(P\left[t^{*}>k\right]-P\left[t^{*}>k+(1)\right) 16\right)
\end{aligned}
$$

where $B(t, k)$ is the time- $t$ discount factor for a $k$-period horizon. We use euro-area swap rates for these. As noted earlier, using swap rates here as "risk free" rates is more in line with the rate that an institutional investor would be able to obtain in practice. By solving (A16) we estimate the CDS-implied hazard rate (i.e. probability of default) for horizon $\tau=k$. We use the bootstrap methodology to iteratively estimate probabilities of default for increasingly longer horizons, using our assumption of a piecewise flat hazard rate function. ${ }^{30}$

\section{A.4.3 Differences}

We now have in hand two measures of the default probability of a sovereign bond - one from sovereign bond prices themselves and the other from CDS written on those bonds. Assuming that the true probability of default is identical in both asset prices, the difference between the two measures is a function of the two markets' relative liquidity conditions. The difference in bond- and CDS-implied default probabilities is our preferred measure of the bonds' (relative) liquidity conditions which we use in our benchmark empirical analysis in Section 3.

\footnotetext{
${ }^{30}$ We assume a quarterly CDS premium payment frequency.
} 


\section{Table A1: Estimation Results (OLS)}

\begin{tabular}{rrrrrrr}
\hline \hline$\beta_{1}$ & $\beta_{2}$ & $\beta_{\text {Def }}$ & $\beta_{\mathrm{AR}}$ & $N$ & $R^{2}$ & $\begin{array}{c}\beta_{1}=\beta_{2} \\
F \text {-statistic }\end{array}$ \\
\hline-17.74 & 13.64 & -3.39 & -0.08 & 464 & 0.401 & 38.28 \\
2.04 & 2.29 & 0.25 & 0.05 & & & $<0.0001$ \\
$(-8.70)$ & $(5.97)$ & $(-13.37)$ & $(-1.71)$ & & & \\
\hline \hline
\end{tabular}

Notes: Weekly data for January 2010 through April 2012, for Ireland, Portugal, Italy and Spain. Coefficients $\beta_{1}, \beta_{2}$ and $\beta_{\text {Def }}$ give basis point response to percentage point change. Generalized least squares with country fixed-effects. Heteroskedasticity robust standard errors in italics underneath point estimates and $t$-statistics in parenthesis underneath. $p$-value from $\chi(1)$ in italics under $F$-stat. 